\title{
Adaptation of striated muscles to Wolframin deficiency in mice: Alterations in cellular bioenergetics
}

\author{
Kersti Tepp ${ }^{\mathrm{a}, *}$, Marju Puurand ${ }^{\mathrm{a}}$, Natalja Timohhina ${ }^{\mathrm{a}}$, Jekaterina Aid-Vanakova ${ }^{\mathrm{a}}$, Indrek Reile ${ }^{\mathrm{b}}$, \\ Igor Shevchuk ${ }^{\mathrm{a}}$, Vladimir Chekulayev ${ }^{\mathrm{a}}$, Margus Eimre ${ }^{\mathrm{c}}$, Nadežda Peet ${ }^{\mathrm{c}}$, Lumme Kadaja ${ }^{\mathrm{c}}$, \\ Kalju Pajuc, Tuuli Käämbre ${ }^{\mathrm{a}}$ \\ ${ }^{a}$ Laboratory of Chemical Biology, National Institute of Chemical Physics and Biophysics, Akadeemia tee 23, 12618 Tallinn, Estonia \\ ${ }^{\mathrm{b}}$ Laboratory of Chemical Physics, National Institute of Chemical Physics and Biophysics, Akadeemia tee 23, 12618 Tallinn, Estonia \\ ${ }^{\mathrm{c}}$ Department of Pathophysiology, Institute of Biomedicine and Translational Medicine, University of Tartu, Ravila 19, 50411 Tartu, Estonia
}

\section{A B S T R A C T}

Background: Wolfram syndrome (WS), caused by mutations in WFS1 gene, is a

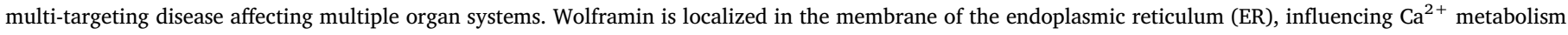

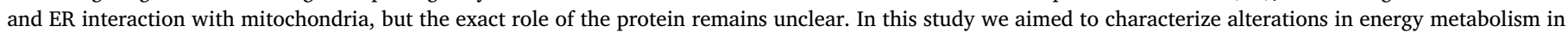
the cardiac and in the oxidative and glycolytic skeletal muscles in Wfs1-deficiency.

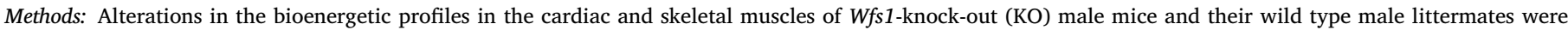
determined using high resolution respirometry, quantitative RT-PCR, NMR spectroscopy, and immunofluorescence confocal microscopy.

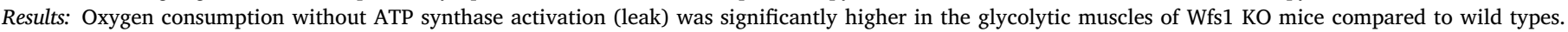
ADP-stimulated respiration with glutamate and malate was reduced in the Wfs1-deficient cardiac as well as oxidative and glycolytic skeletal muscles.

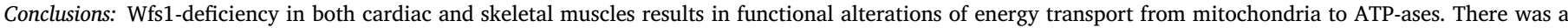

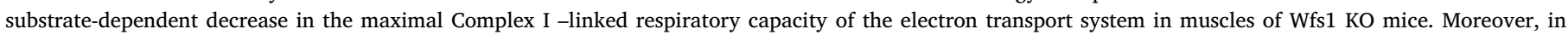
cardiac and gastrocnemius white muscles a decrease in the function of one pathway were balanced by the increase in the activity of the parallel pathway.

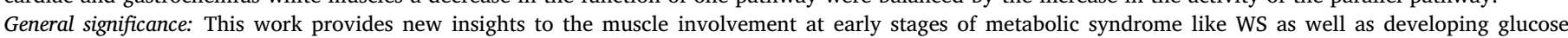
intolerance.

\section{Introduction}

1.1. Wolfram syndrome as a metabolic syndrome simultaneously affecting multiple tissues

Wolfram syndrome (WS) also known as DIDMOAD is an autosomal recessive disorder, caused by mutations in the WFS1 gene which encodes for the protein wolframin [1-3]. It is a multi-targeting disease, having influence on a number of organ systems simultaneously, and causes neuronal degeneration, ataxia and alterations in the performance of cardiac and skeletal muscles [4,5]. The first symptoms of WS are diabetes mellitus (mean age of onset 6 years) and optic atrophy (mean onset at 11 years), followed by diabetes insipidus and deafness. WS is a rare but probably underdiagnosed condition; for example, in a study of 589 diabetic patients in Lebanon 31 new WS cases were found [6].

The Wfs1 gene product wolframin is a transmembrane protein localized in the membrane of the endoplasmic reticulum (ER) $[7,8]$. The exact cellular role of wolframin is still under debate. Most current studies report that wolframin directly or indirectly regulates $\mathrm{Ca}^{2+}$ homeostasis and has an influence on the ER stress response [9-13]. Other studies have additionally demonstrated that wolframin participates in the Mitochondria-Associated ER Membrane (MAM) formation and $\mathrm{Ca}^{2+}$ transport between mitochondria and ER [5,14].

It has been suggested that the development of glucose intolerance in Wfs1 KO mice and WS patients is related to the insufficient insulin secretion which, in turn, is caused by the progressive loss of pancreatic $\beta$-cells due to alterations in cellular $\mathrm{Ca}^{2+}$ signaling [15] and increased ER stress response with the activation of Unfolded Protein Response (UPR) pathways [16-19]. The intracellular mechanisms for progressive loss of the $\beta$-cells and neurodegeneration in Wfs1-deficient animals could be similar. A recent study of mitochondrial function of Wfs1deficient primary rat neuronal cultures revealed that these cells have ER stress, disturbed calcium homeostasis which in turn affects mitochondrial fusion and fission dynamics, decreased mitochondrial membrane potential and cellular ATP content [14]. At the same time, however, the levels of wolframin are high in the cardiac, skeletal

\footnotetext{
* Corresponding author.

E-mail address: kersti.tepp@kbfi.ee (K. Tepp).
} 
muscles, lungs and brown adipose tissue in WT animals, no UPR alterations have been detected in these tissues of Wfs1-deficient mice [17]. Furthermore, compared to changes in the pancreas and neurons that are apparent relatively early in the disease process, functional alterations in the lung and heart tissue emerge later, if at all in WS patients [20,21]. Therefore, the study of cardiac and skeletal muscles of Wfs1 KO animals could be a valuable model to better understand the function of the wolframin, but also diabetes and metabolic syndrome mechanisms in these tissues as well as clarify why these cells are not affected by Wfs1-deficiency related progressive degradation as it occurs in the pancreatic $\beta$-cells and neurons. Currently, the pathways of the differential effects of wolframin deficiency on different organs remain unclear. Studies have demonstrated multiple interacting partners to wolframin and several distinct theories have been proposed about the pathways and timescale of how wolframin deficiency leads to alterations in different organ systems [17,22-25].

Several lines of evidence indicate that WS has common features with mitochondrial diseases. Alterations in mitochondrial DNA (mtDNA) have been found in various tissues, including the skeletal muscles, of several WS patients with conflicting results concerning mitochondrial respiratory system function [26-30]. In addition, silencing of Wfs1 gene in HEK cells has been shown to cause significant changes in the transcription of several genes related to mitochondrial dysfunction and apoptosis [25]. However, in a study of seven Spanish WS patients no mtDNA abnormalities were found in blood samples [31].

Alterations in skeletal muscle energy metabolism in Wfs1-deficient animals and in WS-patients are poorly described. Human muscles comprise approximately $40 \%$ of the body mass. Skeletal muscles contribute significantly to basal energy metabolism and serve as storage for important substrates such as amino acids and carbohydrates. In addition, skeletal muscles are responsible for a great majority of insulinmediated glucose uptake [32]. During hyperglycemia, muscles are the main tissue responsible for non-insulin mediated glucose uptake. Therefore, disruptions of glucose metabolism, that are associated with WS, could also be present in skeletal muscles.

Recently, there have been some descriptions of heart diseases among WS patients, mostly due to structural alterations [6,33,34]. In a study of Lebanese population, out of the 31 WS patients, 5 cases with cardiac abnormalities were found [6], which is significantly higher than in normal population. At the cellular level, Cagalinec et al. (2019) described altered $\mathrm{Ca}^{2+}$ metabolism in the cardiomyocytes of the Wfs1deficient rats. They found that myocytes of the left ventricle had increased contractility (both amplitude and duration of the contraction) due to the prolonged cytosolic calcium transients. The authors proposed that this is caused by the upregulation of RyR2 receptors which is related to the wolframin deficiency [23]. Furthermore, sinus tachycardia and atrial and ventricular arrhythmias have been reported in some patients in an extensive case study of WS patients [35].

To fully understand the function of wolframin, it is important to clarify the mechanisms of varying offset of the disease in different tissues; describe the alterations in skeletal and cardiac muscles in Wfs1 deficiency and determine the mechanisms by which muscles are less affected compared to pancreatic $\beta$-cells and neurons even though Wfs1 gene is highly expressed in the heart. As described above, there is ample evidence that wolframin influences the mitochondrial metabolism either directly or indirectly through altered ER, $\mathrm{Ca}^{2+}$ homeostasis and MAM. The study of oxidative and glycolytic muscles in Wfs1 KO mice enables to estimate the extent of the alterations in the bioenergetic profile in muscles with wolframin deficiency.

\subsection{Regulation of energy metabolism in muscle tissues}

As the energy demand of the oxidative skeletal muscles is permanent but intermittent in intensity, the performance and flexible regulation of energy metabolism is crucial for muscle function. In oxidative skeletal and cardiac muscle cells the oxidative phosphorylation
(OXPHOS) in mitochondria is the main energy source. Therefore, alterations in OXPHOS and transport of high-energy compounds to ATPases have a direct influence on the tissue performance. In muscle cells, the phenomenon called "macromolecular crowding", i.e. high concentrations of macromolecules in the cells, results in extensive diffusion restrictions for metabolites [36,37]. Thus, despite the seemingly close proximity of mitochondria and ATPases, specific phosphotransfer networks are needed for the effective energy transfer from the ATPgenerating sites (mainly mitochondrial matrix) to the ATP-utilizing locations (cytosol, myofibrils) [38]. A key link in high-energy phosphate transport system is the supercomplex Mitochondrial Interactosome (MI) (Fig. 1) that consists of ATP Synthasome (electron transport system, ATP-synthase and inorganic phosphate carrier), Adenine Nucleotide Translocase (ANT), mitochondrial creatine kinase (MtCK) and mitochondrial voltage dependent anion channel (VDAC) [39,40]. The movement of the adenine nucleotides through outer mitochondrial membrane (OMM) is impeded due to the functional interactions of VDAC with specific proteins including hexokinase (HK), beta-tubulin component of free $\alpha \beta$-tubulin heterodimer and other cytoskeletal components such as plectin [41-44]. However, there are no restrictions for the transfer of creatine ( $\mathrm{Cr}$ ) and phosphocreatine (PCr) through the VDAC, so the cytosolic and mitochondrial creatine kinase (CK) isoforms create an opportunity for facilitated energy transport without ADP and ATP free diffusion into the cytoplasm (Fig. 1). In the adenylate kinase (AK) pathway, the mitochondrial AK2 isoform, present in the intermembrane space, facilitates both production and export of ATP by mitochondria. In turn, the cytosolic AK1 isoform, through sequential phosphotransfers, is responsible for the transmission of ATP and the maintenance of the ATP/ADP ratio at ATP-utilization sites [38]. Moreover, compartmentalization of high-energy phosphate carriers between cellular micro-compartments ensures more efficient energy transfer compared to ATP/ADP free diffusion in the cytoplasm $[45,46]$. In the inner mitochondrial membrane (IMM) an electron transport system (ETS), consisting of four complexes, creates the proton gradient to drive ATP synthase. The contribution of each ETS complex to OXPHOS depends on the tissue type; activities of the complexes change during development and aging but alterations in ETS function could be also a sign of disease. For example, in cancer cells there is an increase in Complex II (CII)-linked oxygen consumption rate in comparison with corresponding healthy tissue [47-49].

The role of MI supercomplex together with CK and AK phosphotransfer pathways is to increase the efficiency of the ATP synthesis by the generation of two circuits: (1) transport of the energy to ATPases and (2) quick metabolic feedback signaling (information flux in the form of ADP) back toward mitochondria to fulfill the energy requirement of the cell. Alterations in MI and energy transfer pathways have a direct influence on the muscle performance.

In this study we aimed to assess whether mitochondrial function is impaired in the developing glucose intolerance in Wfs1 KO mice. Using permeabilized muscle fibers, we measured the oxygen consumption rate of ETS with two different protocols, recorded the ADP-dependency of respiration with and without creatine, evaluated the contribution of $\mathrm{AK}$ and CK energy transfer pathway, and the role of HK to regulate the cellular respiration. We additionally assessed the levels of metabolites, structural integrity of the cytoskeleton and the location of cytoskeletal proteins relative to mitochondria using ${ }^{1} \mathrm{H}$ NMR and immunofluorescent confocal microscopy. To our knowledge this is a first study to show functional alterations in intracellular energy transfer networks in the cardiac and skeletal muscles of Wfs1 KO animals.

\section{Methods}

\subsection{Laboratory animals and chemicals}

In all experiments the wild type (WT) male mice and their Wfs1deficient male littermates (age 4-6 months) with 129S6/SvEvTac and 


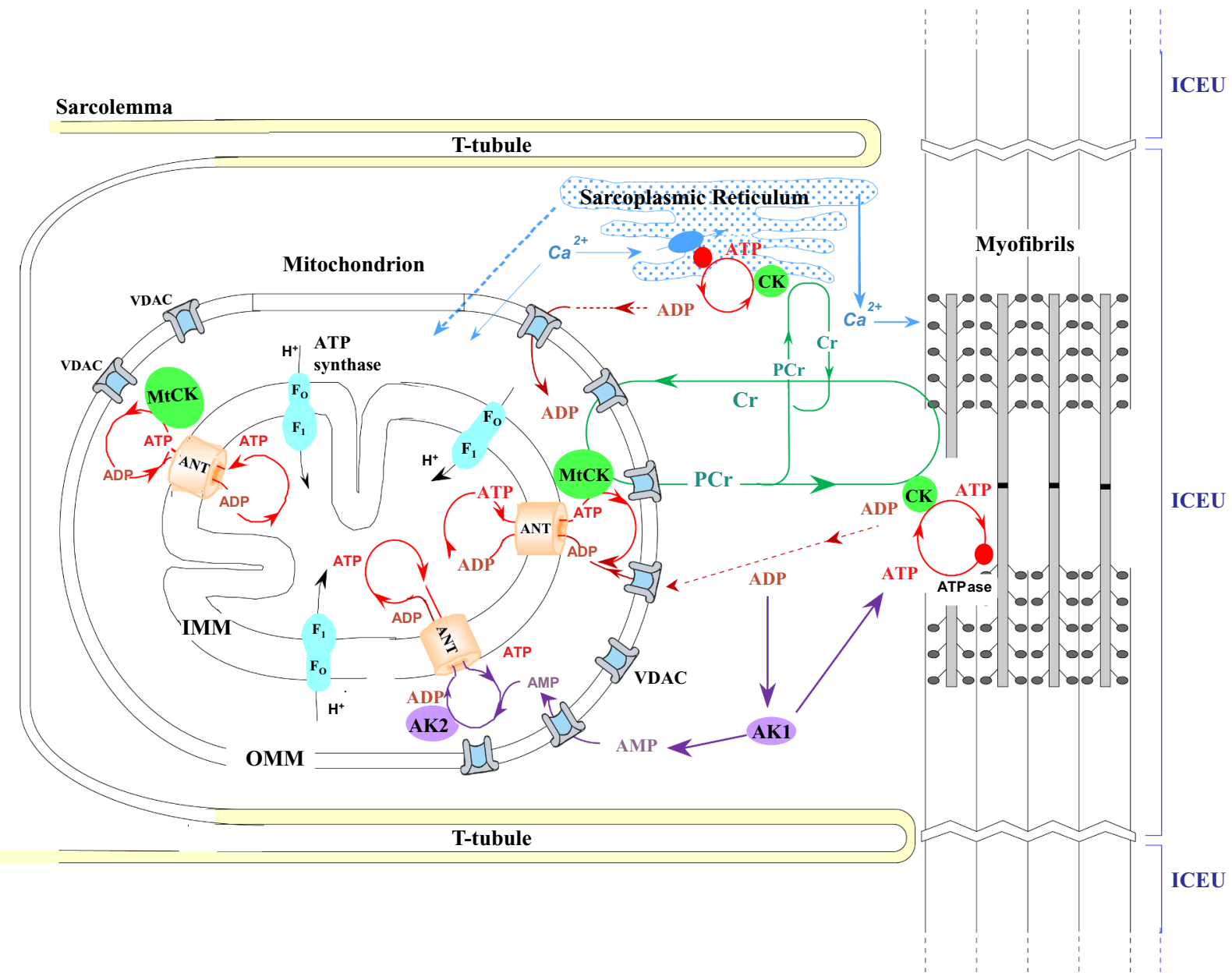

Fig. 1. Regulation of energy metabolism of striated muscle tissues

Oxidative muscle cells are divided into functional sections called Intracellular Energetic Units (ICEU) where mitochondria are in fixed position between the T-tubules in respect of myofibrils. Movement of the adenine nucleotides through outer mitochondrial membrane (OMM) voltage dependent anion channel (VDAC) is impeded due to the functional interactions of VDAC with cytoskeletal protein(s). However, there are no restrictions for movement of creatine (Cr) and phosphocreatine (PCr), so the cytosolic and mitochondrial creatine kinase (CK) isoforms create a circuit for facilitated energy transport without ADP and ATP free diffusion into the cytoplasm. This transport is regulated by supercomplex Mitochondrial Interactosome consisting of ATP Synthase, Adenine Nucleotide Translocase (ANT), mitochondrial CK (MtCK) and VDAC. MtCK transfers phosphate group from ATP to Cr. Produced PCr is moving toward ATPases via CK pathway and ADP is transported directly back to ATP- synthase via ANT. In the adenylate kinase (AK) pathway the mitochondrial AK2 isoform, present in the intermembrane space, facilitates both production and export of ATP by mitochondria. In turn, the cytosolic AK1 isoform, through sequential phosphotransfers, is responsible for the transmission of ATP and maintenance of the ATP/ADP ratio at the ATP-utilization sites. (Modified from [44])

C57BL/6 mixed genetic background were used. Wfs1-deficient mice were generated by replacing most of the coding region of the Wfs1 gene as previously described [50]. Breeding and genotyping of the mice were performed at the Laboratory Animal Centre of the Institute of Biomedicine and Translational Medicine, University of Tartu. The mice were housed under standard laboratory conditions (at constant temperature $22^{\circ} \mathrm{C}$ and a $12: 12 \mathrm{~h} \mathrm{light/dark} \mathrm{cycle} \mathrm{with} \mathrm{free} \mathrm{access} \mathrm{to} \mathrm{food} \mathrm{and} \mathrm{water)}$ in the vivarium of the Department of Chemistry and Biotechnology, Tallinn University of Technology. Animal experiments were approved by the Estonian National Board of Animal Experiments in accordance with the European Communities Directive (86/609/EEC).

Only ultra-pure chemicals suitable for molecular biology and work with cell cultures were used in experiments. All chemicals were purchased from Fluka and Sigma-Aldrich (Saint Louis, MO, USA).

\subsection{Preparation of skinned muscle fibers}

For fiber preparation animals were anaesthetized by intraperitoneal injection of ketamine $(75 \mathrm{mg} / \mathrm{kg})$ and dexmedetomidine $(1 \mathrm{mg} / \mathrm{kg})$, decapitated and skinned fibers were prepared from the heart, $m$. soleus, m. gastrocnemius white (GW) and M. rectus femoris (RF) according to the methods described previously [51]. In order to study the regulation of mitochondrial respiration in muscle fibers, the cells' sarcolemma was permeabilized by saponin treatment $(50 \mu \mathrm{g} / \mathrm{mL})$ for 30 min keeping the mitochondrial membranes intact. Skinned fibers were washed in Mitomedium B solution: (EGTA $(0.5 \mathrm{mM}), \mathrm{MgCl}_{2} \cdot 6 \mathrm{H}_{2} \mathrm{O}(3.0 \mathrm{mM})$, K-lactobionate $(60 \mathrm{mM}), \mathrm{KH}_{2} \mathrm{PO}_{4}(3.0 \mathrm{mM})$, taurine $(20 \mathrm{mM})$, HEPES $(20 \mathrm{mM})$, sucrose $(110 \mathrm{mM})$, dithiothreitol (DTT, $0.5 \mathrm{mM})$, bovine serum albumin (BSA, $5 \mathrm{mg} / \mathrm{mL}$ ) at $\mathrm{pH} 7.1$ supplemented with leupeptin $(1 \mu \mathrm{M})$ for the protection of cytoskeletal proteins from lysosomal proteolysis and kept in the same solution at $4{ }^{\circ} \mathrm{C}$ until used for experiments.

\subsection{Measurements of oxygen consumption}

All experimental measurements of oxygen consumption were determined by a high-resolution respirometry instrument Oxygraph- $2 \mathrm{~K}$ (OROBOROS Instruments, Innsbruck, Austria). Measurements were carried out at $25^{\circ} \mathrm{C}$ in the Mitomedium B solution [51], supplemented with BSA $(5 \mathrm{mg} / \mathrm{mL})$ under continuous magnetic stirring. The permeabilized fiber was weighted and inserted into the oxygraphic chamber 
with respiration media (Mitomedium B solution) supplemented with $0.2 \mu \mathrm{M}$ free $\mathrm{Ca}^{2+}$ and respiratory substrates according to the protocol. The measured oxygen consumption rates are presented as $\mathrm{nmol} \mathrm{O}_{2} / \mathrm{min}$ per mg dry weight.

\subsubsection{Measurement of oxygen consumption kinetics}

The apparent affinity of mitochondria to exogenous ADP (Km(ADP)) characterizes intracellular diffusion restrictions for ADP and varies significantly between different cell types. These differences are caused by specific structural and functional organization of cells' energy metabolism $[52,53]$. In these experiments glutamate ( $\mathrm{G}, 5 \mathrm{mM})$ and malate (M, $2 \mathrm{mM}$ ) were used as respiratory substrates. In order to determine the kinetic constants of exogenous ADP stimulated respiration, the oxygen consumption rates with cumulative addition of ADP was measured. From these data the Km(ADP) values and maximal respiration rates $\left(\mathrm{V}_{\max }\right)$ were calculated using Michaelis-Menten equation. In this study we determined Km(ADP) value for oxidative $m$. soleus and heart muscles in parallel with and without activated CK pathway; Km(ADP) for glycolytic RF and GW muscles was determined without creatine. If a $\mathrm{Km}(\mathrm{ADP})$ in the presence of creatine is significantly lower than the corresponding value without creatine, there exists an effective functional coupling of OXPHOS to CK pathway $[39,52,54]$.

\subsubsection{Determination of the coupled state of mitochondrial creatine kinase}

In order to measure energy flux through CK pathway, the pyruvate kinase/phosphoenol pyruvate (PK/PEP) system was added to trap extramitochondrial ADP. In these conditions we measure only the OXPHOS activated by intramitochondrial ADP/ATP and directly connected with the CK system [39,52,54]. The respiratory solution was supplemented with the following substrates: $G+M$ with addition of PEP ( $5 \mathrm{mM})$. After addition of MgATP ( $2 \mathrm{mM}$ ) to activate ATPases, the injected PK $(10 \mathrm{IU} / \mathrm{mL})$ activates PK/PEP system. While the PK/PEP system rephosphorylates the ADP produced by cytosolic ATPases, the backflow of the ADP to mitochondria is smaller, and the oxygen consumption rate by the OXPHOS inside the mitochondria decreases. Thereafter, creatine was added stepwise until saturation was reached and the maximal respiration rate $\left(\mathrm{V}_{\mathrm{Cr}}\right)$ was detected.

\subsubsection{Estimation the role of cytosolic and mitochondrial adenylate kinase}

For this experiment the respiratory solution was supplemented with respiratory substrates $\mathrm{G}+\mathrm{M}$ with addition of PEP $(5 \mathrm{mM})$. In order to assess the influence of the AK system on the mitochondrial respiration and to distinguish the mitochondrial AK2-dependent respiration rate from the respiration stimulated by the cytosolic AK1, we first added MgATP (2 mM) to activate ATPases and induce maximal endogenous ADP production. Thereafter, AMP $(2 \mathrm{mM})$ was added in order to activate the AK reaction coupled with OXPHOS, involving AK1 and AK2 and to register the maximal AMP stimulated respiration (VAMP). Meanwhile, injection of PK decreases the respiration to the level of coupled reaction between AK2 and ANT inside mitochondria which is demonstrated by $\mathrm{V}_{\mathrm{PK}}$. In order to determine the proportion of respiration independent of $\mathrm{AK}$, the $\mathrm{AK}$ inhibitor diadenosine pentaphosphate (AP5A) was used $\left(\mathrm{V}_{\mathrm{AP} 5 \mathrm{~A}}\right)$.

The AK functional coupling with OXPHOS is represented as AK index (IAK) and was calculated as IAK $=\left(\mathrm{V}_{\mathrm{AMP}}-\mathrm{V}_{\mathrm{AP5A}}\right) / \mathrm{V}_{\mathrm{AP5A}}$. The $\mathrm{AK} 1$ portion of the AK-dependent respiration (IAK1) was calculated as IAK1 $\left.=\left(\left(\mathrm{V}_{\mathrm{AMP}}-\mathrm{V}_{\mathrm{PK}}\right)\right) /\left(\mathrm{V}_{\mathrm{AMP}}-\mathrm{V}_{\mathrm{AP} 5 \mathrm{~A}}\right)\right) * 100 \%[55]$

\subsubsection{Coupling of hexokinases to OXPHOS}

Hexokinases catalyze the first and irreversible step of glycolysis, phosphorylating glucose to glucose-6-phosphate (G6P). In order to measure the ability of HK to stimulate OXPHOS by locally generated ADP in the vicinity of VDAC channel, MgATP was added into the medium supplemented with respiratory substrates $G+M$. The addition of MgATP $(0.1 \mathrm{mM}$ and $2 \mathrm{mM}$ in case of glycolytic and oxidative muscle, respectively) allowed achieving maximal stimulation of mitochondria with endogenous ADP produced by ATPases. Supplementation of glucose $(10 \mathrm{mM})$ activates the HK reaction and $\mathrm{V}_{\mathrm{GLUC}}$ could be registered. Then, the maximal ADP-dependent respiration rate $\left(\mathrm{V}_{\mathrm{ADP}}\right)$ is achieved in the presence of $\mathrm{ADP}(2 \mathrm{mM})$. Addition of cytochrome $c(10 \mu \mathrm{M})$ allowed controlling the quality of the OMM. The glucose index (GI) was calculated as $\left(\mathrm{V}_{\mathrm{GLUC}}-\mathrm{V}_{\mathrm{ATP}}\right) /\left(\mathrm{V}_{\mathrm{ADP}}\right) * 100 \%$ [52].

\subsubsection{Substrate-uncoupler-inhibitor titration (SUIT) protocols}

In order to reconstitute the TCA cycle function and sequential separate branches of mitochondrial pathways for OXPHOS analysis a modified SUIT protocols were used [56]. Permeabilized muscle fibers were added into a chamber where respiration was observed in Mitomedium B solution.

Protocol 1. Titration of substrates, uncouplers and inhibitors were added in sequence. Malate and pyruvate (P, $5 \mathrm{mM}$ ), providing electrons for Complex I (CI) were injected into the chamber to register basal leak oxygen consumption in the absence of adenylates. The addition of ADP $(2 \mathrm{mM})$ stimulated respiration and represented coupled work of CI and phosphorylation system. In order to detect substrates' preference and determine limiting factor for $\mathrm{CI}, \mathrm{G}(5 \mathrm{mM})$ was added into the chamber and the maximal CI-dependent respiration rate was registered. Succinate (S) supports electron transport through CII, thus addition of $\mathrm{S}$ $(10 \mathrm{mM})$ allowed determining the ADP-dependent respiration when electrons are fed to the ETS via CI and CII. Subsequent addition of ADP (final concentration of $5 \mathrm{mM}$ ) stimulated respiration and allowed to control the limitations in the efficiency of ATP synthase [57]. The theoretical maximal capacity of the ETS was evaluated with titration of uncoupler carbonyl cyanide-4-(trifluoromethoxy)phenylhydrazone (FCCP) until saturation of respiration was reached. Subsequent inhibition of CI by rotenone $(2.5 \mu \mathrm{M})$ allowed to determine the CII-linked electron transfer (ET) capacity. Inhibition of Complex III (CIII) by antimycin $\mathrm{A}(10 \mu \mathrm{M})$ allowed to determine the residual oxygen consumption. Addition of $N, N, N^{\prime}, N^{\prime}$-tetramethyl-p-phenylenediamine (TMPD; $1 \mathrm{mM}$ ) demonstrates maximal capacity of complex IV (CIV). Addition of NaCN (1 mM) inhibited cytochrome oxidase (COX) and blocked electron transport, as a result it allowed to detect residual oxygen consumption due to TMPD oxidation reactions [56].

Protocol 2. In the second protocol the contribution of CI and CII to oxygen consumption in skinned muscle fibers was evaluated. First, the mitochondrial respiration rates under nonphosphorylating conditions (basal respiration rate $\left(\mathrm{V}_{0}\right)$ ) with $\mathrm{G}$ and $\mathrm{M}$ in the oxygraphic chamber were registered. Second, after addition of $2 \mathrm{mM}$ ADP the maximum rate of NADH-linked ADP-dependent respiration was detected; subsequently, CI was inhibited by rotenone $(5 \mu \mathrm{M})$. Last, the substrate $S$ $(10 \mathrm{mM})$ was added to activate ETS CII-dependent respiration. From these results the ratio of CII versus CI can be calculated.

\subsection{Immunofluorescence confocal microscopy}

To examine cell architecture and colocalization of mitochondrial VDAC with $\beta$ II-tubulin and plectin in WT and Wfs1 KO mice fibers, confocal microscopy imaging was used. The tissue samples (fibers) were washed with $\mathrm{Ca} / \mathrm{Mg}$ free phosphate buffered saline (PBS) and fixed in $4 \%$ paraformaldehyde (PFA) at $37^{\circ} \mathrm{C}$ for $15 \mathrm{~min}$. After washing step with PBS, the samples were treated with Antigen Retrieval Buffer (Tris $(100 \mathrm{mM})$, urea (5\%), $\mathrm{pH} 9.5)$ at $95^{\circ} \mathrm{C}$ for $5 \mathrm{~min}$. The fibers were washed with PBS and permeabilized with $1 \%$ Triton X-100 at room temperature for $15 \mathrm{~min}$, washed again with PBS and blocked in PBS solution containing $2 \%$ fatty acid free BSA for $1 \mathrm{~h}$ at room temperature. In order to detect VDAC with $\beta \mathrm{II}-$-tubulin the samples were incubated at $4{ }^{\circ} \mathrm{C}$ overnight with primary antibodies: goat polyclonal antibodies for VDAC (sc-32,064) at 1:50 or 1:70 and rabbit monoclonal antibody for $\beta$ II-tubulin (ab170931) at 1:200 or 1:250. After incubation, the samples were washed with $2 \%$ BSA solution and secondary antibodies were used for visualization (Cy3 donkey anti-goat IgG (Abcam, ab97115) at 1:200 
Table 1

Primers for real-time PCR analysis.

\begin{tabular}{ll}
\hline Primer & Sequence $5>3$ \\
\hline \multirow{2}{*}{ ACTB } & F: AGCCATGTACGTAGCCATCCA \\
& R: GACTTTGCTTCCTTGGTCAGG \\
CKB & F: TCGTGGCATATGGCACAATG \\
& R: CGGGTGAACACTTCCTTCATG \\
CKM & F: GTCCGTGGAAGCTCTCAACAG \\
& R: CAGAGGTGACACGGGCTTGT \\
CKMT2 & F: AGCAAGGATCCACGCTTTTCT \\
& R: TCTGCCGATCCGATCTATGTT \\
HPRT1 & F: GCAGTACAGCCCCAAAATGG \\
& R: AACAAAGTCTGGCCTGTATCCAA \\
\hline
\end{tabular}

F: forward; R: reverse.

and donkey anti-rabbit IgG (Alexa Fluor 488, ab150073) at 1:200). To detect and visualize VDAC with plectin the following primary and secondary antibodies were used: rabbit polyclonal antibodies for VDAC (kindly provided by Catherine Brenner) at 1:200, guinea pig polyclonal antibodies for plectin (PROGEN, GP21) at 1:250 and goat anti-rabbit IgG (DyLight 488, ab96895) at 1:200, goat anti-guinea pig IgG (Alexa Fluor 647, ab150187) at 1:250. Samples were incubated with secondary antibodies as described above at room temperature for $2 \mathrm{~h}$ and then washed with $2 \%$ BSA solution, PBS and finally with deionized water. The samples were treated with ProLong Gold antifade reagent (Life Technologies) supplemented with 4',6-diamidino-2-phenylindole dihydrochloride (DAPI, Molecular Probes) for visualizing the cell nucleus and deposited on glass coverslips for observation with confocal microscope (Olympus FluoView FV 10i-W).

\section{5. ${ }^{1} H$ NMR spectroscopy}

For NMR analysis, heart muscle was frozen and powdered in liquid nitrogen. The powder was weighted and subjected to a methanol:water (2:1) extraction. Overnight lyophilized sample material was reconstituted in $0.5 \mathrm{~mL}$ of phosphate buffer $(100 \mathrm{mM}$, pH 7.4). Thereafter, the sample was mixed with 4,4-dimethyl-4-silapentane-1-sulfonic acid (DSS, $1 \mathrm{mM}$ )) in $\mathrm{D}_{2} \mathrm{O}$ standard solution in ratio 9:1. The liquid amounts were determined gravimetrically. All experiments were performed at room temperature $\left(25^{\circ} \mathrm{C}\right)$ in 256 scans on a Bruker Avance III $800.13 \mathrm{MHz}$ spectrometer equipped with a triple resonance inversed (TXI) probe. Chemical shifts were referenced and all concentrations calculated as a fold change compared to the DSS $(0.1 \mathrm{mM})$ internal standard signal.

\subsection{Determination of enzymatic activities}

Pieces of muscles were snap frozen in liquid nitrogen and stored at $-80^{\circ} \mathrm{C}$. The samples were allowed to thaw at $0{ }^{\circ} \mathrm{C}$ and homogenized in the medium containing the following: EDTA $(1 \mathrm{mM})$, DTT $(1 \mathrm{mM})$, glucose $(10 \mathrm{mM}), \mathrm{MgCl}_{2}(5 \mathrm{mM})$, HEPES $(5 \mathrm{mM})$, Triton $\mathrm{X}-100(0.1 \%)$ and leupeptin $(5 \mu \mathrm{g} / \mathrm{mL}$ ), at $\mathrm{pH} 8$ (maintained by $\mathrm{NaOH}$ ) by UltraTurrax T25 homogenizer (IKA, Germany) on ice.

After homogenization the homogenates were left on ice for $1 \mathrm{~h}$ to allow complete extraction of the enzymes. Measurement of HK activity was performed using a spectrophotometer Lambda 900 (Perkin Elmer, U.S.) in solution containing Tris- $\mathrm{HCl}(50 \mathrm{mM})$, glucose $(20 \mathrm{mM})$, DTT (0.3) mM, NADP (0.6 mM), MgATP (2 mM), glucose-6-phosphate dehydrogenase (G6PD) $(2 \mathrm{IU} / \mathrm{mL}), \mathrm{pH} 7.6$, adjusted at $25^{\circ} \mathrm{C}$. The rate of NADPH formation was monitored after addition of homogenate at $340 \mathrm{~nm}$ [58]. For CK activity measurements solution containing glucose $(20 \mathrm{mM})$, AMP $(20 \mathrm{mM})$, DTT $(0.3 \mathrm{mM})$, magnesium acetate $(3 \mathrm{mM})$, MgADP (1 mM), NADP (1 mM), Tris-HCl (50 mM) (pH 7.4, $\left.25^{\circ} \mathrm{C}\right)$, HK $(2 \mathrm{IU} / \mathrm{mL})$, and $\mathrm{G} 6 \mathrm{PD}(2 \mathrm{IU} / \mathrm{mL})$ at $25^{\circ} \mathrm{C}$ was used. After stabilization of the optical density, the reaction was started by adding $20 \mathrm{mM} \mathrm{PCr}$ and the rate of NADPH formation was registered [59]. AK activity measurements were performed in solution containing Tris- $\mathrm{HCl}(20 \mathrm{mM})$ (pH 8, at $\left.30^{\circ} \mathrm{C}\right), \mathrm{KCl}(15 \mathrm{mM})$, DTT (0.33 mM), NADH (0.24 mM), PEP $(0.8 \mathrm{mM})$, ATP $(1 \mathrm{mM})$, lactate dehydrogenase $(3 \mathrm{IU} / \mathrm{mL})$ and PK 6 (IU/ $\mathrm{mL})$. After registration of the basal ATPase activity, AMP $(1.3 \mathrm{mM})$ was added and from the following changes in NADH oxidation rates at $340 \mathrm{~nm}$, the AK activity was calculated [59].

\subsection{Gene expression study}

Total RNA was isolated by using the RNeasy Mini Kit (Qiagen). Genomic DNA wipeout and reverse transcription was performed by using Quantitect ${ }^{\circledR}$ Reverse Transcription Kit (Qiagen) according to manufacturer's protocol (Quantitect ${ }^{\circledast}$ Reverese Transcription Handbook, 2005). Real-time PCR amplification was carried out with mouse gene-specific primers (Proligo, France and Oligomer OY, Finland, Table 1) using QuantiTect SYBR Green PCR Kit (Qiagen, Germany). The process of collecting fluorescence data during PCR was performed by StepOnePlus ${ }^{\mathrm{TM}}$ real-Time PCR Instrument (Applied Biosystems, USA). The relative target quantity in samples was determined by the comparative threshold cycle $(\Delta \mathrm{CT}, \Delta \Delta \mathrm{CT})$ method [60]. Measurements were normalized to multiple endogenous control genes: ACTB, B2M or HPRT1. The relative quantity of target in each sample was assessed by comparing normalized target quantity in each sample to normalized target quantity in the reference sample.

\subsection{Statistical analysis}

Results are expressed as the mean \pm standard error of the mean (SEM). To determine statistical significance between age groups, oneway analysis of variance (ANOVA) test was performed and $p$ values $<.05$ were considered significant.

The proton NMR spectra of all samples (one sample corresponds to one mouse) were subjected to principal component analysis on Mestrenova version 12 .

\section{Results}

\subsection{Alterations in kinetic profile and substrate preferences (Km(ADP) and SUIT protocols)}

In skeletal and cardiac muscles a contiguous energy supply for ATPases in myofibrils and ion channels is crucial for muscle work. In oxidative muscles the predominant site of the ATP synthesis is the mitochondrion where proton gradient is formed by ETS and the ADP phosphorylation is regulated by MI supercomplex.

The capability of Wfs1 KO and WT muscle cell mitochondria to generate ATP was followed using oxygraphic measurements with (1) SUIT (substrate-uncoupler-inhibitor-titration) protocol [56], (2) substrate-inhibitor protocol to determine the individual capacity of CI- and CII-linked ET, and (3) classical ADP-titration protocol to determine the kinetic constants like apparent Michaelis-Menten constant for ADP (Km (ADP) $)$ and the maximal respiration rate $\left(\mathrm{V}_{\max }\right)$. With these protocols the respiration linked to different pathways of the ETS can be followed simultaneously to the preference of the pathways to specific substrates.

In the SUIT protocol, $\mathrm{P}+\mathrm{M}$ were first inserted as CI-linked substrates, and thereafter ADP was added to activate OXPHOS in mitochondria $\left(\mathrm{V}_{\mathrm{ADP}}\right)$. Subsequently, glutamate was injected to detect the effect of different CI-linked substrates on OXPHOS ( $\left.\mathrm{V}_{\mathrm{GLUT}}\right)$. We observed that the Leak respiration (oxygen consumption without adenylates) in these conditions was statistically higher in Wfs1-deficient soleus, RF and GW muscles but not in the cardiac muscle (Fig. 2A).

In the presence of $\mathrm{P}+\mathrm{M}$ and ADP, the CI-linked OXPHOS was significantly different only in GW muscle where both the $\mathrm{V}_{\mathrm{ADP}}$ and $\mathrm{V}_{\mathrm{GLUT}}$ values were lower in $\mathrm{Wfs} 1 \mathrm{KO}$ animals compared to WT (Table 2). After addition of S (CII - linked substrate) the increase in respiration rate was significantly higher in Wfs1 KO mice GW muscle in 


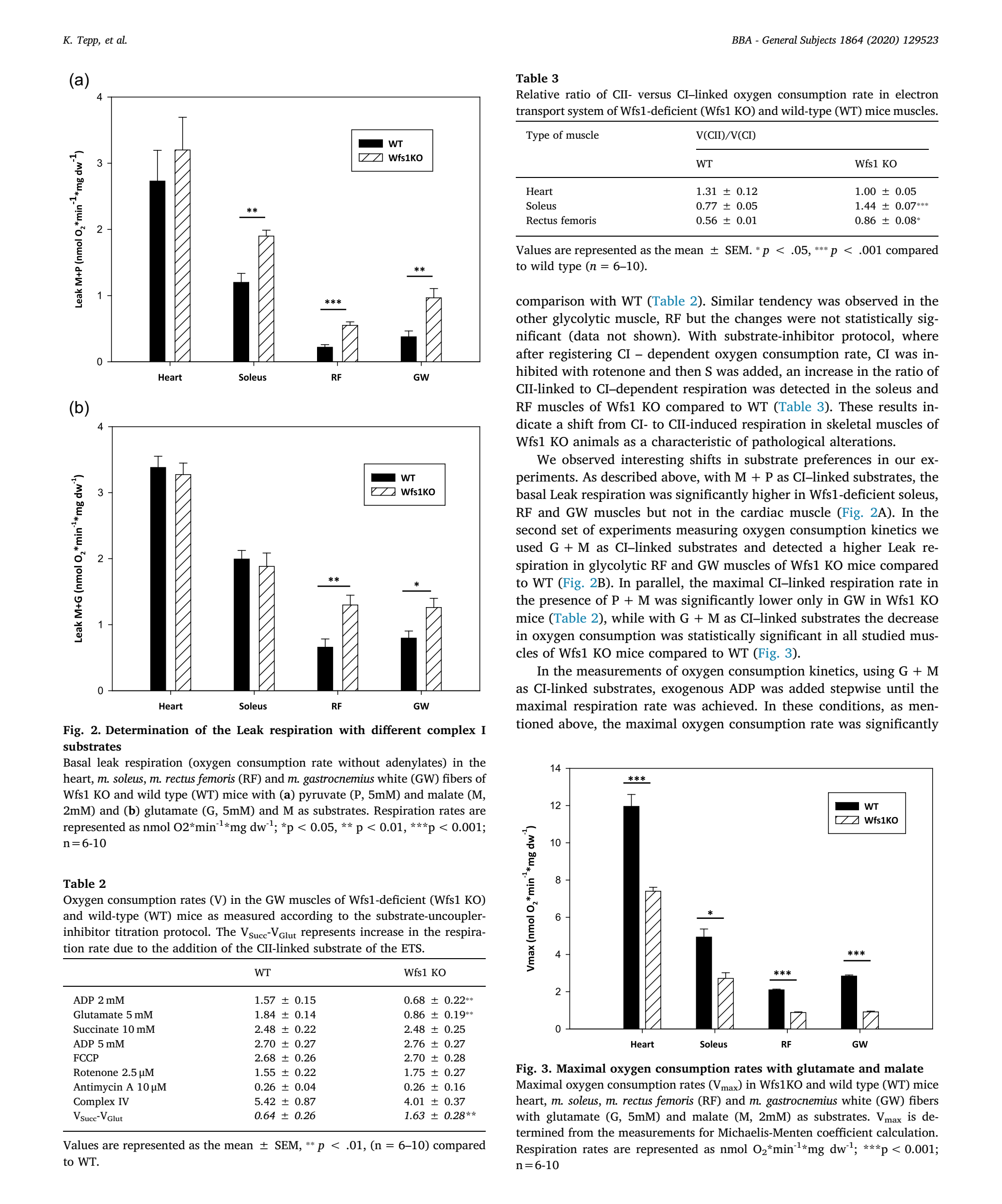


Table 4

Michaelis-Menten constant Km(ADP) values in the muscles of Wfs1-deficient (Wfs1 KO) and wild-type (WT) animals with $(+\mathrm{Cr})$ and without $(-\mathrm{Cr})$ activation of creatine kinase pathway.

\begin{tabular}{llll}
\hline Km(ADP) & & \\
\hline Type of muscle & & $-\mathrm{Cr}$ & $+\mathrm{Cr}$ \\
\hline \multirow{2}{*}{ Heart } & WT & $101.6 \pm 21.3$ & $42.7 \pm 5.0$ \\
& Wfs1 KO & $54.2 \pm 5.2$ & $41.4 \pm 3.0$ \\
Soleus & WT & $463 \pm 78.9$ & $62.4 \pm 15.4$ \\
& Wfs1 KO & $482 \pm 78.2$ & $50.3 \pm 16.8$ \\
RF & WT & $6.45 \pm 0,64$ & - \\
& Wfs1 KO & $18.99 \pm 3.15$ & - \\
GW & WT & $10.36 \pm 1.02$ & - \\
& Wfs1 KO & $12.64 \pm 2.29$ & - \\
& &
\end{tabular}

Values are represented as nmolO2* $\min ^{-1 *} \mathrm{mg} \mathrm{dw}^{-1}$, means \pm SEM are shown $\mathrm{n}=6-10$. RF- $M$. rectus femoris, GW- m. Gastrocnemius white.

lower in all measured Wfs1 KO mice muscle fibers compared to WT animals (Fig. 3). In parallel, Km(ADP) values did not show prominent kinetic differences between Wfs1 KO and WT skeletal muscle fibers (Table 4). However in the cardiac muscle fibers we detected a decrease in the $\mathrm{Km}(\mathrm{ADP})$ value (100 versus $50 \mu \mathrm{M}$ ADP in WT and Wfs $1 \mathrm{KO}$ respectively), but in the presence of $\mathrm{Cr}$, mimicking better physiological conditions, Km(ADP) values in the study group and WT animals were similar.

In conclusion, the results of oxygraphic measurements, characterizing ETS revealed increased Leak respiration in both GW and RF glycolytic skeletal muscles in the presence of $\mathrm{M}+\mathrm{G}$, as well as increased Leak respiration in the soleus, RF and GW muscle fibers in the presence of $\mathrm{M}+\mathrm{P}$. The maximal CI-dependent oxygen consumption rate in the presence of $\mathrm{G}+\mathrm{M}$ decreased in all followed Wfs1 KO muscles compared to WT. In the presence of P + M, a decrease in the CI-linked ADPstimulated respiration rate was detectable only in Wfs1 KO GW muscle compared to WT. These results indicate some alterations in glutamate metabolism, having no influence on the metabolism of pyruvate. In addition, in GW muscle the CII-linked respiration was significantly higher in Wfs1 KO muscle compared to WT. A similar shift was also detected in the soleus and RF muscles when the capacities of ETS complexes were measured independently.

These measurements were performed in conditions where energy transfer pathways from mitochondrion to ATPases in the cell were not activated. To investigate how the transport of the energy from mitochondrion to ATP-ases influences OXPHOS, we next investigated the three most important systems for energy facilitation in skeletal muscles.

\subsection{Energy transfer pathways}

Intracellular transfer of ATP from mitochondria to ATPases is impeded; thus, special energy transfer pathways are essential for maintaining steady energy balance at different ATP consumption sites in the cell. Facilitated transport of metabolites is especially important in oxidative muscle cells like the heart and soleus, where most of the ATP is synthesized in mitochondria; alteration in these pathways has immediate influence on the cellular metabolism as a whole. It has been demonstrated that the main energy transport system in the oxidative skeletal and heart muscles is the CK/PCr pathway [40,45,61], followed by the AK pathway $[38,62]$. In oxidative muscle cells, one of the manifestations of the effectiveness of the CK pathway is the increased affinity of mitochondria toward ADP (decrease in the Km(ADP) value) when the pathway is activated. In glycolytic GW and RF muscles the Km (ADP) value is low because there is no impediment for the ADP/ATP through the VDAC in the OMM. Therefore, it is not possible to determine the role of CK transfer with this method in these muscles. The effect of activation of CK pathway on Km(ADP) value was detected in the mutant and WT soleus and WT heart muscle fibers (Table 4). The (a)

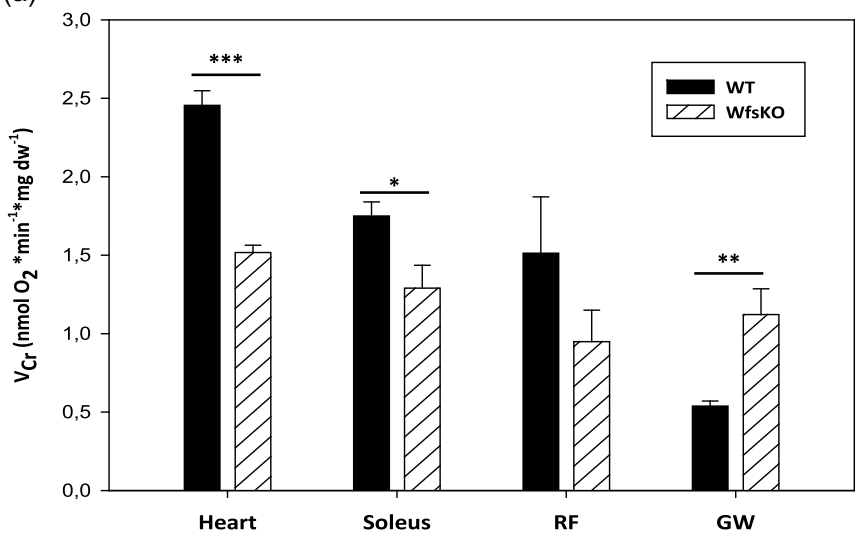

(b)

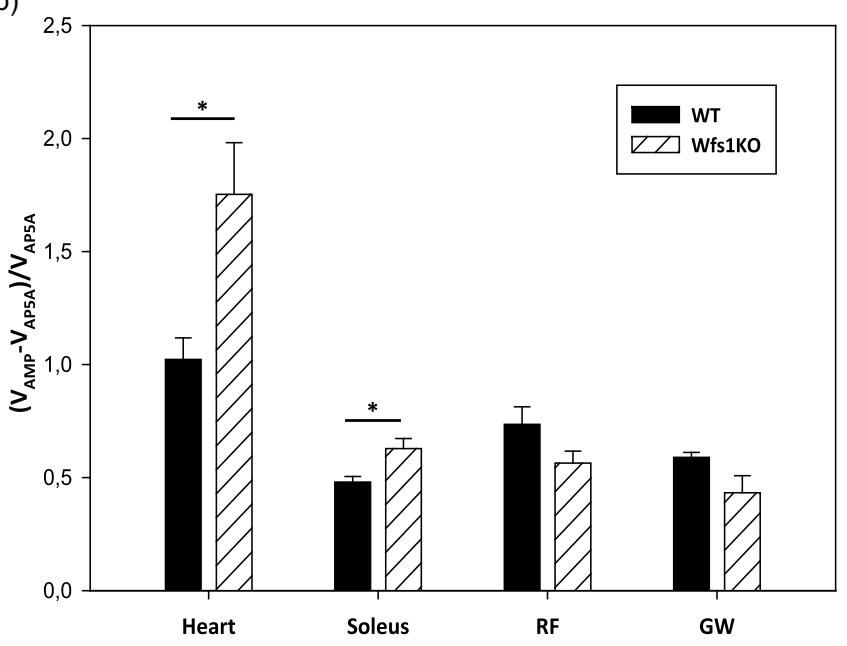

(c)

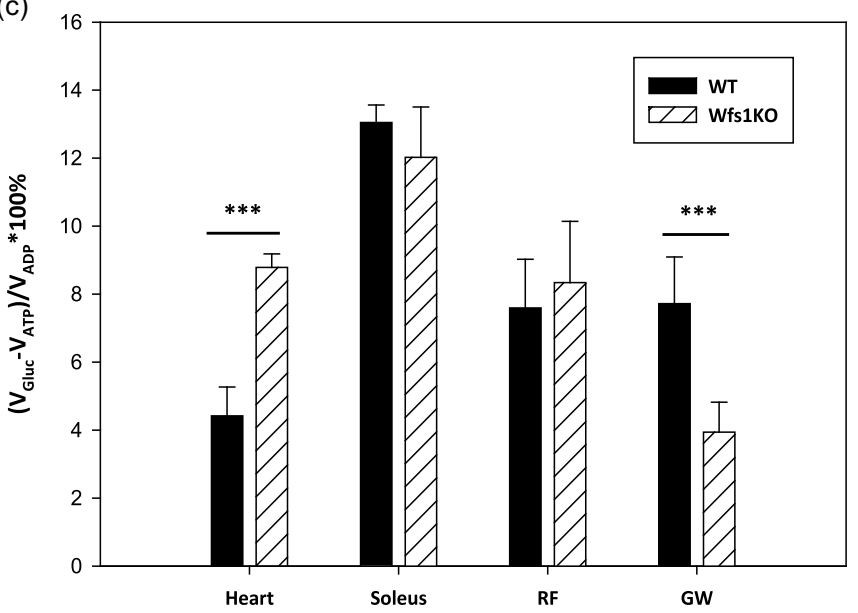

Fig. 4. Quantification of functional coupling between OXPHOS and energy transfer pathways

(a) Oxygen consumption rates measured with the maximal activation of the creatine kinase pathway. Respiration rates are represented in $\mathrm{nmol}_{2}{ }^{*} \mathrm{~min}$ ${ }^{1 *} \mathrm{mg} \mathrm{dw}^{-1}$.

(b) Functional coupling of oxygen consumption with adenylate kinase (AK) pathway is represented as $\mathrm{AK}$ index (IAK) calculated as IAK $=\left(\mathrm{V}_{\mathrm{AMP}}-\mathrm{V}_{\mathrm{AP5A}}\right)$ / $\mathrm{V}_{\mathrm{APSA}}$ where $\mathrm{V}_{\mathrm{AMP}}$ is oxygen consumption rate at the maximal activation of $\mathrm{AK}$ system and $\mathrm{V}_{\mathrm{AP} 5 \mathrm{~A}}$ in the presence of $\mathrm{AK}$ inhibitor.

(c) Functional coupling of hexokinase (HK) to OXPHOS. The glucose index (GI) was calculated as $\left(\mathrm{V}_{\mathrm{GLUC}}-\mathrm{V}_{\mathrm{ATP}}\right) /\left(\mathrm{V}_{\mathrm{ADP}}\right) * 100 \%$ where $\left(\mathrm{V}_{\mathrm{GLUC}}-\mathrm{V}_{\mathrm{ATP}}\right)$ is the increase in the oxygen consumption rate in response to addition of $10 \mathrm{mM}$ glucose and $\mathrm{V}_{\mathrm{ADP}}$ is the respiration rate in the presence of $2 \mathrm{mM} \mathrm{ADP}$; $\mathrm{p}<0.05$, $* * \mathrm{p}<0.01,{ }^{* * *} \mathrm{p}<0.001 ; \mathrm{n}=6-10$ 
Table 5

Enzyme activities of Wfs1-deficient (Wfs1 KO) and wild-type (WT) mice muscles. Values are represented as $n m^{*} \min ^{-1 *} \mathrm{mg} \mathrm{ww}^{-1}(n=5-8)$

\begin{tabular}{|c|c|c|c|}
\hline Enzyme & Type of muscle & WT & Wfs1 KO \\
\hline \multirow[t]{4}{*}{ Creatine kinase } & Heart & $262.5 \pm 32.6$ & $304.1 \pm 16.7$ \\
\hline & Soleus muscle & $870.8 \pm 101.4$ & $443.3 \pm 32.6^{* *}$ \\
\hline & $\begin{array}{l}\text { Rectus femoris } \\
\text { muscle }\end{array}$ & $3072.1 \pm 180.2$ & $1579.2 \pm 224.6^{* * *}$ \\
\hline & $\begin{array}{l}\text { Gastrocnemius } \\
\text { muscle }\end{array}$ & $3495.4 \pm 226.5$ & $3088.1 \pm 142.9$ \\
\hline \multirow{4}{*}{$\begin{array}{r}\text { Adenylate } \\
\text { kinase }\end{array}$} & Heart & $176.0 \pm 28.5$ & $179.8 \pm 22.8$ \\
\hline & Soleus muscle & $350.8 \pm 18.5$ & $196.0 \pm 10.9^{* * * *}$ \\
\hline & $\begin{array}{l}\text { Rectus femoris } \\
\text { muscle }\end{array}$ & $399.8 \pm 37.6$ & $205.4 \pm 48.9^{* *}$ \\
\hline & $\begin{array}{l}\text { Gastrocnemius } \\
\text { muscle }\end{array}$ & $636.9 \pm 60.8$ & $654.8 \pm 43.9$ \\
\hline \multirow[t]{4}{*}{ Hexokinase } & Heart & $7.2 \pm 0.5$ & $8.0 \pm 0.7$ \\
\hline & Soleus muscle & $3.80 \pm 0.11$ & $3.43 \pm 0.10^{*}$ \\
\hline & $\begin{array}{l}\text { Rectus femoris } \\
\text { muscle }\end{array}$ & $1.53 \pm 0.09$ & $2.14 \pm 0.18^{* *}$ \\
\hline & $\begin{array}{l}\text { Gastrocnemius } \\
\text { muscle }\end{array}$ & $2.58 \pm 0.12$ & $2.85 \pm 0.05$ \\
\hline
\end{tabular}

Values are represented as the means \pm SEM. ${ }^{*} p<.05$, ${ }^{* *} p<.01$, *** $p<.001$ compared to wild type.

$\mathrm{Km}(\mathrm{ADP})$ value in the heart fibers of Wfs1 KO animals was already lower without $\mathrm{Cr}$, so we observed no further significant decrease as a response to the CK pathway activation (Table 4).

In the second protocol we used PK/PEP system for trapping all ADP generated by ATPases. Under these conditions, the registered oxygen consumption is directly dependent only on the ADP/ATP circulation incorporated in the MI and CK transfer system. The maximal $\mathrm{Cr}$ activated OXPHOS rate $\left(\mathrm{V}_{\mathrm{Cr}}\right)$ in Wfs1 KO oxidative muscle (heart and soleus) fibers was decreased compared to WT and the alteration was more pronounced in the heart muscle (Fig. 4A). In contrast, in glycolytic GW the $\mathrm{V}_{\mathrm{Cr}}$ was higher in fibers of Wfs1 KO mice than in WT. There was some decrease in $\mathrm{V}_{\mathrm{Cr}}$ in $\mathrm{RF}$ muscle but the change was not significant (Fig. 4A).

In parallel, the total CK enzyme activities of in the wolframin-deficient soleus and RF muscle were $\sim 2$ times decreased but there were no differences detected in the heart and GW compared to WT tissues (Table 5). Recent proteomic results also showed no change of CK isoenzyme levels in the wolframin-deficient heart [63]. Consequently, lower oxygen consumption rate with activated creatine kinase pathway in Wfs1-deficient heart (Fig. 4A) could be mostly caused by the weakened interaction between mitochondrial CK and ANT and thereby impaired MI function.

Additionally, a study of the abundance of CK isoforms in RF demonstrated lower muscle-type CK isoform (CK-MM) mRNA level of Wfs1-deficient mice than in their WT littermates (Table 6). As CK-MM is known to be functionally coupled with ER $\mathrm{Ca}^{2+}$-ATPase [64], the capability of CK-MM to phosphorylate ADP, produced by myofibrillar or ER ATPases, can be reduced and thereby induce local ATP deficiency. It leads to the impairment of muscle contraction and the other ERlinked energy-consuming processes. However, here we found that the expression of mitochondrial CK coding gene CKMT2 did not differ significantly $(p=.213)$ between these two groups (Table 6).

Table 6

Relative mRNA levels of $\mathrm{CK}$ isoforms in $M$. rectus femoris of Wfs1-deficient (Wfs1 KO) and wild-type mice (WT).

\begin{tabular}{llll}
\hline & CKB & CKM & CKMT2 \\
\hline WT mice, & $0.03 \pm 0.01$ & $199.0 \pm 38.9$ & $2.42 \pm 0.43$ \\
Wfs1 KO mice, & $0.04 \pm 0.01$ & $93.5 \pm 9.5 *$ & $3.42 \pm 0.61$
\end{tabular}

Values are represented as the means \pm SEM. ${ }^{*} p<.05$ compared to wild type $(n=6)$.
The other main energy pathway in muscle cells is AK pathway. In Fig. 4B, the AK activation was presented as maximal AK oxygen consumption relative to the oxygen consumption independent of the AK system - AK Index (see 2.3.3. Methods). In oxidative, heart and soleus muscles there is a significant increase in the AK Index value in the fibers of Wfs1 KO mice compared to the WT fibers (Fig. 4B). Nevertheless, in soleus muscle the activity measurements of the tissue homogenates demonstrated a significant decrease in the AK activity (Table 5). This controversy needs future study, but it could be explained by the different approach of the experiments. In the enzyme activity evaluation, all the AK isoforms located in the tissue were included, while in the presented oxygraphic measurements only the AK, connected with transfer of high-energy phosphates from mitochondria to ATPases were followed. In glycolytic muscles, GW and RF, no significant change was detected in AK Index; however, we observed a trend toward decreased $\mathrm{AK}$ index in both muscles. Additionally, when looking at the total AK activity measurements, the decrease in AK activity in Wfs1 KO mice RF muscle was statistically significant (Table 5).

In addition, we measured the relative contribution of $\mathrm{AK}$ isoforms to the overall AK-related oxygen consumption flux using a protocol developed in our laboratory [52,55]. The role of cytosolic (AK1) isoform varies from $\sim 60 \%$ in soleus to $\sim 80 \%$ in heart muscle (Table S1 in supplements); however, despite some increase in the contribution of AK1 isoform in the GW muscle Wfs1 KO mice, the differences between Wfs1-deficient and WT mice muscles were not statistically significant.

The third investigated energy transfer system is the glycolytic pathway. These data are represented as the glucose index (GI) calculated as the ratio of the relative increase in OXPHOS rate due to the glucose addition to the maximal respiration rate with exogenous ADP. The GI characterizes the functional coupling of OXPHOS with glycolysis. According to our results, there are some interesting shifts in the GI values: in the oxidative heart muscle of the Wfs1 KO animals the GI is higher compared to WT; in the glycolytic GW muscle fibers, the normally high GI value decreases in KO animals (Fig. 4C). In parallel, the total HK activity in heart and GW muscle of Wfs1 KO animals were similar to wild type (Table 5).

Taking together, the alterations in the AK related oxygen consumption in the cardiac and soleus muscle cells are the opposite of those taking place with CK-related respiration (Fig. 4). Consequently, in the oxidative muscles of Wfs1 $\mathrm{KO}$ animals the role of CK energy transfer system is decreasing and at the same time, functional coupling of mitochondria with AK is increasing when compared to the muscles of WT animals. These shifts from one energy transfer pathway to the other may indicate a compensatory mechanism in energy metabolism. As the CK pathway activity is lower in oxidative muscle cells of Wfs1 KO animals, the AK and HK pathway may help to manage the energy flow from mitochondrion to the ATPases, especially in the cardiac muscle. Increase in the GI value in the cardiac muscle cells is registered during aging of the rat heart cardiomyocytes [65]. In the cardiomyocytes of young healthy animals the GI is very low, around 1\%; during aging it increases to $8.2 \%$ at the age of 1.5 years.

\subsection{H NMR studies of the heart muscle}

Metabolites in tissue water soluble extracts of 4-6 month mice were determined using ${ }^{1} \mathrm{H}$ NMR spectroscopy. The total creatine content of KO animals was not different from that of the WT. The principal component analysis of proton NMR spectra did not reveal any systematic differences between the two mouse genotypes. We also calculated the values of six abundant metabolites: glucose, lactate, alanine, glutamine, glutamate and taurine (Supplementary Table 2). The concentrations of these metabolites were similar as presented before by Zervou et al. 2016 [66]. We did not find any statistically significant differences between the KO and WT groups. Our results are in good accordance with the study by Porosk et al. (2017) were they compared the heart metabolome of six month old Wfs1 KO and WT mice [67]. Therefore, the 


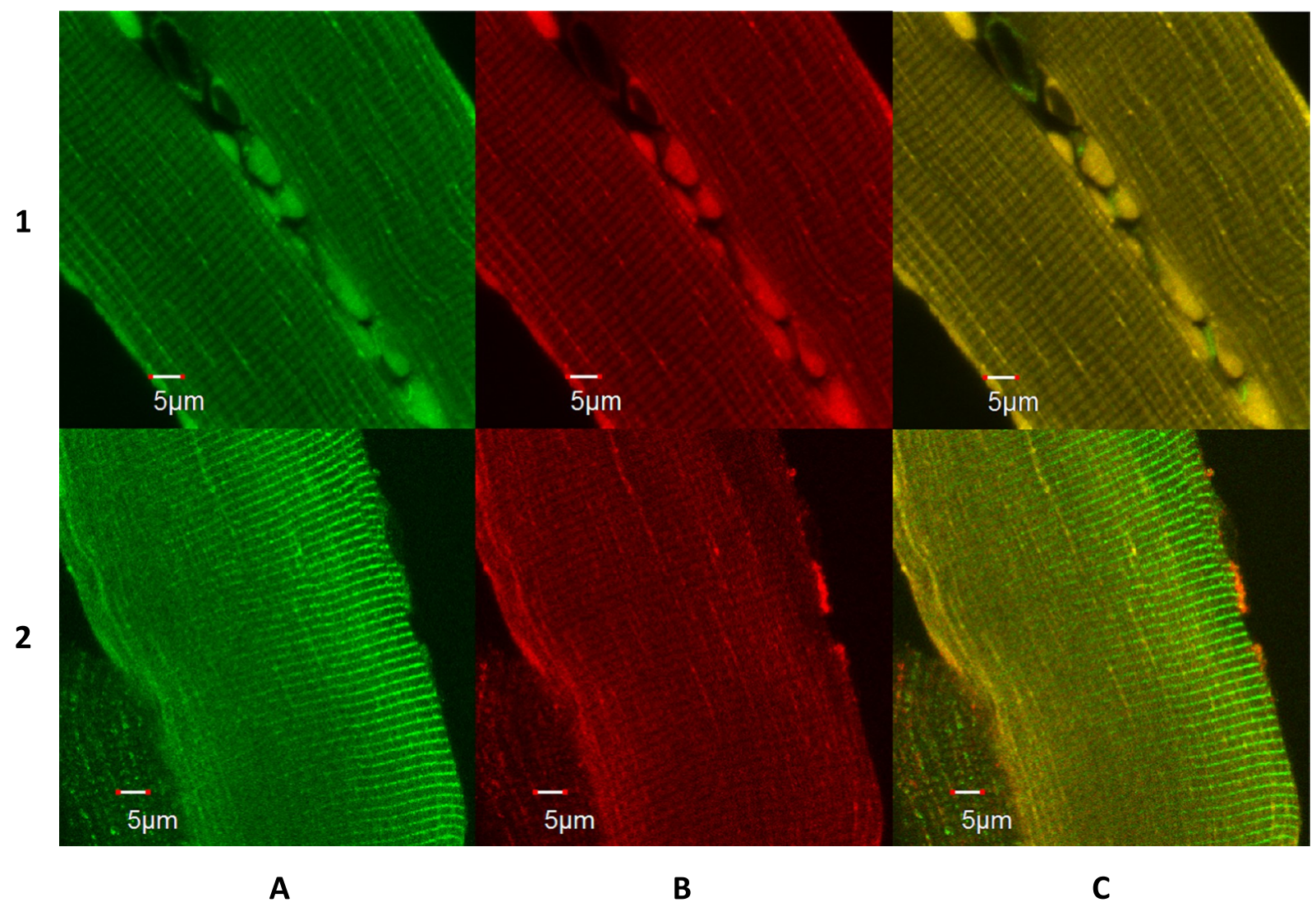

Fig. 5. Evaluation of the interaction between mitochondria and tubulin

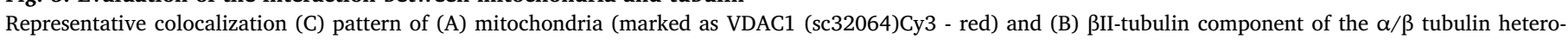

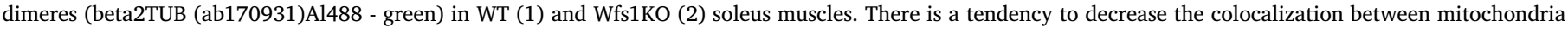
and tubulin; calculated Pearson's coefficients are 0.93 and 0.54 for WT and for Wfs1KO, respectively.

alterations in the regulation of CK pathway could be a significant sign of functional disturbances in the cardiac muscle energy metabolism.

\subsection{Structural changes - confocal microscopy}

The energy metabolism regulation in the muscle cell mitochondria is directly dependent on the functional interaction of mitochondrial VDAC with cytoskeletal proteins, one of which is probably $\beta$-tubulin component of the free $\alpha \beta$-tubulin heterodimers $[41,68,69]$. According to our visual and manual observations the skeletal muscles of WFS1 KO mice are softer and more delicate then WT muscles. However, the animals have no difficulties to manage their movement in captivated/cage conditions. We used confocal microscopy to follow if this observation is accompanied with changes in the structure of the muscle cell. We used antibodies for VDAC and BII-tubulin in one combination (Fig. 5) and VDAC with plectin in another. Some alterations were detected in calculated Pearson's coefficients in muscle fibers of Wfs1 KO animals compared to WT, but these changes could not be considered as significant in the given context. As the age of the animals in our experiments was 4-6month, there is a possibility that more prominent changes could develop later in the course of the disease.

\section{Discussion}

Recently, several theories about the pathways of the WS and the possible roles of wolframin have been presented. The placement of the wolframin in the ER membrane has been demonstrated and the involvement of the protein in cell metabolism through homeostasis of $\mathrm{Ca}^{2+}$ has found most proponents. However, several questions still remain unanswered. A few studies have investigated the effects of WS in the muscle tissue, specifically in the bioenergetic metabolism. Some patient reviews indicate that the incidences of congenital heart defects are significantly higher among WS patients [33,34]. However, large functional alterations have been not detected in all patients. A possible reason for the lower number of reports about changes in the muscle tissues in WS patients could be that more emphasis is placed on the pathological conditions that emerge first in the disease process (e.g. pancreatic $\beta$-cell and neuronal changes) and thus affect the life quality in higher extent. Furthermore, as the life expectancy of the WS patients is reduced, smaller changes in physiology may occur unnoticed. However, to understand the mechanisms and roles of the wolframin protein, different tissues should be studied.

In this study, by studying 4-6 month old Wfs1 KO and WT mice, we detected some regulatory kinetic alterations in the apparent affinity of exogenous ADP to mitochondrion and some decline in the colocalization pattern between mitochondria and tubulin in soleus muscle of Wfs1 KO mice. Therefore, we may conclude that there are no critical structural changes in muscle cells and the functional interactions between mitochondria and cytoskeleton are generally intact. However, we observed significant changes in several aspects of OXPHOS and in the functional properties of the electron transport system and pathways, transporting high energy bond to the ATPases.

With both substrate combinations used for CI-linked respiration, increase in the Leak or basal Leak respiration was detected in the glycolytic muscles in Wfs1 KO compared to WT mice. This value demonstrates oxygen consumption in the non-phosphorylating conditions, i.e. proton leak through the IMM, across lipid bilayers without ATP-synthase activation. This result indicates inefficiency of the OXPHOS system and may be a sign of the functional changes in the IMM. These findings are in accordance with the research of Eimre et al. (2018) [70] 
as they found an increase in the Leak respiration in the RF muscle of aged, 9-12 month old mice together with increased uncoupler protein 2 mRNA levels. In addition, they found that the citrate synthase activity and amount of ETS subunits as well as mitochondrial proteins was increased in the glycolytic RF muscle, while no important alteration was detected in oxidative cardiac and soleus muscle of Wfs1 KO compared to WT mice. Moreover, it has been demonstrated that the basal Leak respiration is related to the amount of ANT and other anion carrier proteins in mitochondria [71], but not with the activity of these protein complexes [72]. Thus, the increase in the Leak respiration could be connected to the alterations in the IMM composition or increase in the ANT abundance, which could be caused by an increase in the number of MI in mitochondria as an adaptive response to the less efficient ATP production in the $\mathrm{Wfs} 1 \mathrm{KO}$ animals.

In all the muscle types studied, we observed that the maximal ADPdependent respiration rate with $\mathrm{G}+\mathrm{M}$ was lower in the Wfs1 KO animals compared to WT. Interestingly, when P + M was used as CIlinked substrate, we found no significant differences between Wfs1 KO and WT. These results indicate that the wolframin deficiency has caused some alterations in the cell which have influence on the glutamate but not on the pyruvate metabolism. WS is characterized by increased ER stress, decrease in the number of mitochondria-ER connecting sites, and disturbances in $\mathrm{Ca}^{2+}$ homeostasis. These changes could have an influence on the activity of protein complexes regulating glutamate metabolism in mitochondria such as glutamate-aspartate antiporter (AGC) and 2-oxoglutarate-malate transporter. It has been demonstrated that $\mathrm{Ca}^{2+}$ related alterations in AGC1 (which is also expressed in the cardiac and skeletal muscle) is one of the causes of the autism spectrum disorder [73]. As the alterations in $\mathrm{Ca}^{2+}$ metabolism have also been detected in WS, these changes may also have an influence on the glutamate-related oxygen consumption rate here. Furthermore, in a study of cardiac cells with induced ER stress, Prola et al. (2019) detected a decrease in the glutamate- and succinate- but not in pyruvate-induced respiration. They concluded that fatty acid oxidation pathway in mitochondria is down-regulated in cells with ER stress while relative oxidation of pyruvate is increased [74]. These results are in a good accordance with the current study as we found that the GI was increased in the heart fibers of Wfs1 KO mice compared to WT.

The transport of high energy bond from mitochondria to ATPases is a crucial part of the energy provision. Our study demonstrated that there are several alterations in the pathways responsible for energy trafficking. We found an important shift taking place in the heart muscle of the Wfs1 KO mice. In healthy cardiac muscle cells the CK has a leading role in the transport of the phosphoryl group to ATPases. In the cardiac cells of Wfs1 KO animals the oxygen consumption rate of the creatine stimulated respiration is decreasing, while the role of the secondary AK pathway is increasing. Simultaneously, the functional interaction with glycolytic enzymes, represented as the glucose index, is higher in cardiac muscle of the Wfs1 KO animals. In glycolytic GW muscle, a contrary shift is taking place: in WT GW muscle, high GI was determined, but it was decreased significantly in the GW fibers of Wfs1 KO mice. In parallel, there was a significant increase in the CK pathway-related respiration in the wolframin deficient animals. Similar alterations in the pathway preferences are detected in the aging heart muscle [65] and in pathological conditions such as cancer [48]. These changes indicate possible compensatory mechanisms as a response to altered metabolism in the muscle cells: a decrease in the CK pathway is balanced by an increase in the AK system in the heart muscle. Similarly, in GW muscle a shift from glycolytic to CK pathway is taking place.

Using ${ }^{1} \mathrm{H}$ NMR, we detected no significant alterations in the metabolites profile of Wfs1 KO animals. This relative stability may be achieved due to the compensatory mechanism in the energy transfer pathways which enable to continue the muscle work at lower efficiency. We speculate that the problems might arise during in vivo conditions when the workload of the muscle has to be increased.

The results of our study indicate adaptations in the bioenergetic metabolism of the muscles to the alterations caused by the Wfs 1 deficiency. We observed no crucial structural alterations, but clear functional changes in the MI and energy transport were detected. It was visible that in some muscles a decrease in the one pathway was balanced by the increase in the activity of parallel pathway. There was no direct decrease in the CI-linked ET capacity, but rather change in the substrate preference profile, which might have been caused by the alterations connected with ER stress. These results are in accordance with the study of skeletal muscle of young adults with type I diabetes, where no changes in mitochondrial content or distribution have been detected, but mitochondrial oxidative capacity has been shown to decrease [75].

It has been demonstrated that wolframin is highly expressed in the cardiac as well as in the skeletal muscles. There are some reports of atrial and ventricular arrhythmias and sinus tachycardia in the later stages of WS [35]; however, the extent of the impairment is significantly smaller in comparison with the ones that emerge earlier in the neurons and pancreatic $\beta$-cells. Adaptations in muscle tissue as a response to the wolframin deficiency, detected in our study, could explain the contradiction. Yet, as the WS-accompanied alterations in oxidative muscle cells are not essential, the role of wolframin might be more complex and include additional functions regulating $\mathrm{Ca}^{2+}$ homeostasis.

In sum, WS is a metabolic disease with complicated diagnostics. Several cases have been described where patients with WS are misdiagnosed and treated for diabetes for years [33,34]. Better mechanistic understanding of wolframin functions could enable the development of methods for earlier diagnosis of WS, and for possible treatments in order to postpone the manifestations of the disease such as optical nerve degradation or diabetes. Our results demonstrate that WS is a mitochondrial disease and monitoring functional alterations in striated muscle bioenergetics could be considered as one of the directions for the better understanding of wolframin functions and for developing improved diagnostic methods for WS.

\section{Contributions}

K.T. and M.P. designed, preformed and interpreted all oxygraphic experiments with input from J.A.-V., N.T. and N.P.; L.K. developed gene expression study protocols and analyzed and interpreted all of the quantitative RT-PCR data; I.R. conducted NMR spectroscopy and analyzed the data; I.S. and V.C. performed immunohistochemistry experiments and corresponding data analysis; M.E. determined enzyme activities; K.P. supplied Wfs1 KO mice and coordinated work from the University of Tartu; T.K. coordinated and supervised work from NICPB; K.T., M.P., and M.E. wrote the manuscript with help from J.A.-V. and T.K.

\section{Declaration of Competing Interest}

Authors declare no conflict of interest.

\section{Acknowledgments}

This work was supported by Institutional Research Funding IUT231, and IUT20-46 of the Estonian Ministry of Education and Research, by Mobilitas Pluss program MOBTP51 of the Estonian Ministry of Education and Research; by Center of Excellence of the Archimedes Foundation and European Regional Development Fund Project No. TK134 and by the European Union's Horizon 2020 research and innovation program TRANSGENO project under grant agreement No. 668989.The authors thank Kadi Vaher for the proofreading.

\section{Appendix A. Supplementary data}

Supplementary data to this article can be found online at https:// 
doi.org/10.1016/j.bbagen.2020.129523.

\section{References}

[1] T.G. Barrett, S.E. Bundey, A.R. Fielder, P.A. Good, Optic atrophy in Wolfram (DIDMOAD) syndrome, Eye (Lond) 11 (Pt 6) (1997) 882-888.

[2] T.G. Barrett, S.E. Bundey, Wolfram (DIDMOAD) syndrome, J. Med. Genet. 34 (1997) 838-841.

[3] L. Rigoli, F. Lombardo, C. Di Bella, Wolfram syndrome and WFS1 gene, Clin. Genet. 79 (2011) 103-117, https://doi.org/10.1111/j.1399-0004.2010.01522.x.

[4] F. Urano, Wolfram syndrome: diagnosis, management, and treatment, Curr. Diabetes Rep. 16 (2016) 6, , https://doi.org/10.1007/s11892-015-0702-6.

[5] B. Delprat, T. Maurice, C. Delettre, Wolfram syndrome: MAMs' connection? Cell Death Dis. 9 (2018) 364, , https://doi.org/10.1038/s41419-018-0406-3.

[6] R. Medlej, J. Wasson, P. Baz, S. Azar, I. Salti, J. Loiselet, A. Permutt, G. Halaby, Diabetes mellitus and optic atrophy: a study of Wolfram syndrome in the Lebanese population, J. Clin. Endocrinol. Metab. 89 (2004) 1656-1661, https://doi.org/10. 1210/jc.2002-030015.

[7] K. Takeda, H. Inoue, Y. Tanizawa, Y. Matsuzaki, J. Oba, Y. Watanabe, K. Shinoda, Y. Oka, WFS1 (Wolfram syndrome 1) gene product: predominant subcellular localization to endoplasmic reticulum in cultured cells and neuronal expression in rat brain, Hum. Mol. Genet. 10 (2001) 477-484, https://doi.org/10.1093/hmg/10.5. 477.

[8] S. Hofmann, C. Philbrook, K.D. Gerbitz, M.F. Bauer, Wolfram syndrome: structural and functional analyses of mutant and wild-type wolframin, the WFS1 gene product, Hum. Mol. Genet. 12 (2003) 2003-2012, https://doi.org/10.1093/hmg/ ddg214.

[9] S.G. Fonseca, M. Fukuma, K.L. Lipson, L.X. Nguyen, J.R. Allen, Y. Oka, F. Urano, WFS1 is a novel component of the unfolded protein response and maintains homeostasis of the endoplasmic reticulum in pancreatic beta-cells, J. Biol. Chem. 280 (2005) 39609-39615, https://doi.org/10.1074/jbc.M507426200.

[10] D. Takei, H. Ishihara, S. Yamaguchi, T. Yamada, A. Tamura, H. Katagiri, Y. Maruyama, Y. Oka, WFS1 protein modulates the free $\mathrm{Ca}(2+)$ concentration in the endoplasmic reticulum, FEBS Lett. 580 (2006) 5635-5640, https://doi.org/10. 1016/j.febslet.2006.09.007.

[11] S. Lu, K. Kanekura, T. Hara, J. Mahadevan, L.D. Spears, C.M. Oslowski, R. Martinez, M. Yamazaki-Inoue, M. Toyoda, A. Neilson, P. Blanner, C.M. Brown, C.F. Semenkovich, B.A. Marshall, T. Hershey, A. Umezawa, P.A. Greer, F. Urano, A calcium-dependent protease as a potential therapeutic target for Wolfram syndrome, Proc. Natl. Acad. Sci. U. S. A. 111 (2014) E5292-E5301, https://doi.org/10. 1073/pnas.1421055111.

[12] M. Zatyka, C. Ricketts, G. da Silva Xavier, J. Minton, S. Fenton, S. Hofmann-Thiel, G.A. Rutter, T.G. Barrett, Sodium-potassium ATPase 1 subunit is a molecular partner of Wolframin, an endoplasmic reticulum protein involved in ER stress, Hum. Mol. Genet. 17 (2008) 190-200, https://doi.org/10.1093/hmg/ddm296.

[13] A.A. Osman, M. Saito, C. Makepeace, M.A. Permutt, P. Schlesinger, M. Mueckler, Wolframin expression induces novel ion channel activity in endoplasmic reticulum membranes and increases intracellular calcium, J. Biol. Chem. 278 (2003) 52755-52762, https://doi.org/10.1074/jbc.M310331200.

[14] M. Cagalinec, M. Liiv, Z. Hodurova, M.A. Hickey, A. Vaarmann, M. Mandel, A. Zeb, V. Choubey, M. Kuum, D. Safiulina, E. Vasar, V. Veksler, A. Kaasik, Role of mitochondrial dynamics in neuronal development: mechanism for Wolfram syndrome, PLoS Biol. 14 (2016) e1002511, , https://doi.org/10.1371/journal.pbio.1002511.

[15] J.R. Porter, T.G. Barrett, Monogenic syndromes of abnormal glucose homeostasis: clinical review and relevance to the understanding of the pathology of insulin resistance and beta cell failure, J. Med. Genet. 42 (2005) 893-902, https://doi.org/ 10.1136/jmg.2005.030791.

[16] H. Ishihara, S. Takeda, A. Tamura, R. Takahashi, S. Yamaguchi, D. Takei, T. Yamada, H. Inoue, H. Soga, H. Katagiri, Y. Tanizawa, Y. Oka, Disruption of the WFS1 gene in mice causes progressive beta-cell loss and impaired stimulus-secretion coupling in insulin secretion, Hum. Mol. Genet. 13 (2004) 1159-1170, https:// doi.org/10.1093/hmg/ddh125.

[17] T. Yamada, H. Ishihara, A. Tamura, R. Takahashi, S. Yamaguchi, D. Takei, A. Tokita, C. Satake, F. Tashiro, H. Katagiri, H. Aburatani, J. Miyazaki, Y. Oka WFS1-deficiency increases endoplasmic reticulum stress, impairs cell cycle progression and triggers the apoptotic pathway specifically in pancreatic beta-cells, Hum. Mol. Genet. 15 (2006) 1600-1609, https://doi.org/10.1093/hmg/ddl081.

[18] Y. Ohta, A. Taguchi, T. Matsumura, H. Nakabayashi, M. Akiyama, K. Yamamoto, R. Fujimoto, R. Suetomi, A. Yanai, K. Shinoda, Y. Tanizawa, Clock gene dysregulation induced by chronic ER stress disrupts beta-cell function, EBioMedicine 18 (2017) 146-156, https://doi.org/10.1016/j.ebiom.2017.03.040.

[19] S. Morikawa, T. Tajima, A. Nakamura, K. Ishizu, T. Ariga, A novel heterozygous mutation of the WFS1 gene leading to constitutive endoplasmic reticulum stress is the cause of Wolfram syndrome, Pediatr. Diabetes 18 (2017) 934-941, https://doi. org/10.1111/pedi.12513.

[20] T.M. Strom, K. Hortnagel, S. Hofmann, F. Gekeler, C. Scharfe, W. Rabl, K.D. Gerbitz, T. Meitinger, Diabetes insipidus, diabetes mellitus, optic atrophy and deafness (DIDMOAD) caused by mutations in a novel gene (wolframin) coding for a predicted transmembrane protein, Hum. Mol. Genet. 7 (1998) 2021-2028.

[21] H. Luuk, S. Koks, M. Plaas, J. Hannibal, J.F. Rehfeld, E. Vasar, Distribution of Wfs1 protein in the central nervous system of the mouse and its relation to clinical symptoms of the Wolfram syndrome, J. Comp. Neurol. 509 (2008) 642-660, https://doi.org/10.1002/cne.21777.

[22] C. Angebault, J. Fauconnier, S. Patergnani, J. Rieusset, A. Danese, C.A. Affortit, J. Jagodzinska, C. Megy, M. Quiles, C. Cazevieille, J. Korchagina, D. Bonnet-
Wersinger, D. Milea, C. Hamel, P. Pinton, M. Thiry, A. Lacampagne, B. Delprat, C. Delettre, ER-mitochondria cross-talk is regulated by the $\mathrm{Ca}(2+)$ sensor NCS1 and is impaired in Wolfram syndrome, Sci. Signal. 11 (2018), https://doi.org/10.1126/ scisignal.aaq1380.

[23] M. Cagalinec, A. Zahradnikova, A. Zahradnikova Jr., D. Kovacova, L. Paulis, S. Kurekova, M. Hot'ka, J. Pavelkova, M. Plaas, M. Novotova, I. Zahradnik, Calcium signaling and contractility in cardiac myocyte of Wolframin deficient rats, Front. Physiol. 10 (2019) 172, https://doi.org/10.3389/fphys.2019.00172.

[24] S. Gharanei, M. Zatyka, D. Astuti, J. Fenton, A. Sik, Z. Nagy, T.G. Barrett, Vacuolartype $\mathrm{H}+$-ATPase V1A subunit is a molecular partner of Wolfram syndrome 1 (WFS1) protein, which regulates its expression and stability, Hum. Mol. Genet. 22 (2013) 203-217, https://doi.org/10.1093/hmg/dds400.

[25] S. Koks, R.W. Overall, M. Ivask, U. Soomets, M. Guha, E. Vasar, C. Fernandes, L.C. Schalkwyk, Silencing of the WFS1 gene in HEK cells induces pathways related to neurodegeneration and mitochondrial damage, Physiol. Genomics 45 (2013) 182-190, https://doi.org/10.1152/physiolgenomics.00122.2012.

[26] S. Hofmann, R. Bezold, M. Jaksch, B. Obermaier-Kusser, S. Mertens, P. Kaufhold, W. Rabl, W. Hecker, K.D. Gerbitz, Wolfram (DIDMOAD) syndrome and Leber hereditary optic neuropathy (LHON) are associated with distinct mitochondrial DNA haplotypes, Genomics 39 (1997) 8-18, https://doi.org/10.1006/geno.1996.4474.

[27] D. Pilz, O.W. Quarrell, E.W. Jones, Mitochondrial mutation commonly associated with Leber's hereditary optic neuropathy observed in a patient with Wolfram syndrome (DIDMOAD), J. Med. Genet. 31 (1994) 328-330, https://doi.org/10.1136/ jmg.31.4.328.

[28] A. Barrientos, J. Casademont, A. Saiz, F. Cardellach, V. Volpini, A. Solans, E. Tolosa, A. Urbano-Marquez, X. Estivill, V. Nunes, Autosomal recessive Wolfram syndrome associated with an 8.5-kb mtDNA single deletion, Am. J. Hum. Genet. 58 (1996) 963-970.

[29] A. Rotig, V. Cormier, P. Chatelain, R. Francois, J.M. Saudubray, P. Rustin, A. Munnich, Deletion of mitochondrial DNA in a case of early-onset diabetes mellitus, optic atrophy, and deafness (Wolfram syndrome, MIM 222300), J. Clin. Invest. 91 (1993) 1095-1098, https://doi.org/10.1172/JCI116267.

[30] M.J. Jackson, L.A. Bindoff, K. Weber, J.N. Wilson, P. Ince, K.G. Alberti, D.M. Turnbull, Biochemical and molecular studies of mitochondrial function in diabetes insipidus, diabetes mellitus, optic atrophy, and deafness, Diabetes Care 17 (1994) 728-733, https://doi.org/10.2337/diacare.17.7.728.

[31] E. Domenech, M. Gomez-Zaera, V. Nunes, Study of the WFS1 gene and mitochondrial DNA in Spanish Wolfram syndrome families, Clin. Genet. 65 (2004) 463-469, https://doi.org/10.1111/j.1399-0004.2004.00249.x.

[32] A.D. Baron, G. Brechtel, P. Wallace, S.V. Edelman, Rates and tissue sites of noninsulin- and insulin-mediated glucose uptake in humans, Am. J. Phys. 255 (1988) E769-E774, https://doi.org/10.1152/ajpendo.1988.255.6.E769.

[33] M.A. Ganie, B.A. Laway, S. Nisar, M.M. Wani, M.L. Khurana, F. Ahmad, S. Ahmed, P. Gupta, I. Ali, I. Shabir, A. Shadan, A. Ahmed, S. Tufail, Presentation and clinical course of Wolfram (DIDMOAD) syndrome from North India, Diabet. Med. 28 (2011) 1337-1342, https://doi.org/10.1111/j.1464-5491.2011.03377.x.

[34] H.A. Korkmaz, K. Demir, F. Hazan, M. Yildiz, O.N. Elmas, B. Ozkan, Association of Wolfram syndrome with Fallot tetralogy in a girl, Arch. Argent. Pediatr. 114 (2016) e163-e166, https://doi.org/10.5546/aap.2016.eng.e163.

[35] B.T. Kinsley, M. Swift, R.H. Dumont, R.G. Swift, Morbidity and mortality in the Wolfram syndrome, Diabetes Care 18 (1995) 1566-1570, https://doi.org/10.2337/ diacare.18.12.1566

[36] V. Saks, A.V. Kuznetsov, M. Gonzalez-Granillo, K. Tepp, N. Timohhina, M. KaruVarikmaa, T. Kaambre, P. Dos Santos, F. Boucher, R. Guzun, Intracellular energetic units regulate metabolism in cardiac cells, J. Mol. Cell. Cardiol. 52 (2012) 419-436, https://doi.org/10.1016/j.yjmcc.2011.07.015.

[37] M. Vendelin, N. Béraud, K. Guerrero, T. Andrienko, A.V. Kuznetsov, J. Olivares, L. Kay, V.A. Saks, Mitochondrial regular arrangement in muscle cells: a "crystal-like" pattern, Am. J. Physiol. Cell Physiol. 288 (2005) C757-C767, https://doi.org/10. 1152/ajpcell.00281.2004.

[38] P.P. Dzeja, A. Terzic, Phosphotransfer networks and cellular energetics, J. Exp. Biol. 206 (2003) 2039-2047, https://doi.org/10.1242/jeb.00426.

[39] N. Timohhina, R. Guzun, K. Tepp, C. Monge, M. Varikmaa, H. Vija, P. Sikk, T. Kaambre, D. Sackett, V. Saks, Direct measurement of energy fluxes from mitochondria into cytoplasm in permeabilized cardiac cells in situ: some evidence for mitochondrial interactosome, J. Bioenerg. Biomembr. 41 (2009) 259-275, https:// doi.org/10.1007/s10863-009-9224-8.

[40] K. Tepp, I. Shevchuk, V. Chekulayev, N. Timohhina, A.V. Kuznetsov, R. Guzun, V. Saks, T. Kaambre, High efficiency of energy flux controls within mitochondrial interactosome in cardiac intracellular energetic units, Biochim. Biophys. Acta 1807 (2011) 1549-1561, https://doi.org/10.1016/j.bbabio.2011.08.005.

[41] M. Puurand, K. Tepp, N. Timohhina, J. Aid, I. Shevchuk, V. Chekulayev, T. Kaambre, Tubulin betaII and betaIII isoforms as the regulators of VDAC channel permeability in health and disease, Cells 8 (2019), https://doi.org/10.3390/ cells8030239.

[42] K. Mado, V. Chekulayev, I. Shevchuk, M. Puurand, K. Tepp, T. Kaambre, On the role of tubulin, plectin, desmin, and vimentin in the regulation of mitochondrial energy fluxes in muscle cells, Am. J. Physiol. Cell Physiol. 316 (2019) C657-C667, https:// doi.org/10.1152/ajpcell.00303.2018.

[43] A. Klepinin, L. Ounpuu, K. Mado, L. Truu, V. Chekulayev, M. Puurand, I. Shevchuk, K. Tepp, A. Planken, T. Kaambre, The complexity of mitochondrial outer membrane permeability and VDAC regulation by associated proteins, J. Bioenerg. Biomembr. 50 (2018) 339-354, https://doi.org/10.1007/s10863-018-9765-9.

[44] V.A. Saks, T. Kaambre, P. Sikk, M. Eimre, E. Orlova, K. Paju, A. Piirsoo, F. Appaix, L. Kay, V. Regitz-Zagrosek, E. Fleck, E. Seppet, Intracellular energetic units in red muscle cells, Biochem. J. 356 (2001) 643-657, https://doi.org/10.1042/ 
bj3560643.

[45] V. Saks, U. Schlattner, M. Tokarska-Schlattner, T. Wallimann, R. Bagur, S. Zorman, M. Pelosse, P.D. Santos, F. Boucher, T. Kaambre, R. Guzun, Systems level regulation of cardiac energy fluxes via metabolic cycles: role of Creatine, phosphotransfer pathways, and AMPK Signaling, Springer Ser. Biophys. 16 (2014) 261-320, https:// doi.org/10.1007/978-3-642-38505-6 11.

[46] R. Guzun, T. Kaambre, R. Bagur, A. Grichine, Y. Usson, M. Varikmaa, T. Anmann, K. Tepp, N. Timohhina, I. Shevchuk, V. Chekulayev, F. Boucher, P. Dos Santos, U. Schlattner, T. Wallimann, A.V. Kuznetsov, P. Dzeja, M. Aliev, V. Saks, Modular organization of cardiac energy metabolism: energy conversion, transfer and feedback regulation, Acta Physiol. 213 (2015) 84-106, https://doi.org/10.1111/apha 12287.

[47] V. Chekulayev, K. Mado, I. Shevchuk, A. Koit, A. Kaldma, A. Klepinin, N. Timohhina, K. Tepp, M. Kandashvili, L. Ounpuu, K. Heck, L. Truu, A. Planken, V. Valvere, T. Kaambre, Metabolic remodeling in human colorectal cancer and surrounding tissues: alterations in regulation of mitochondrial respiration and metabolic fluxes, Biochem. Biophys. Rep. 4 (2015) 111-125, https://doi.org/10. 1016/j.bbrep.2015.08.020.

[48] A. Kaldma, A. Klepinin, V. Chekulayev, K. Mado, I. Shevchuk, N. Timohhina, K. Tepp, M. Kandashvili, M. Varikmaa, A. Koit, M. Planken, K. Heck, L. Truu, A. Planken, V. Valvere, E. Rebane, T. Kaambre, An in situ study of bioenergetic properties of human colorectal cancer: the regulation of mitochondrial respiration and distribution of flux control among the components of ATP synthasome, Int. J. Biochem. Cell Biol. 55 (2014) 171-186, https://doi.org/10.1016/j.biocel.2014.09. 004.

[49] M. Puurand, N. Peet, A. Piirsoo, M. Peetsalu, J. Soplepmann, M. Sirotkina, A. Peetsalu, A. Hemminki, E. Seppet, Deficiency of the complex I of the mitochondrial respiratory chain but improved adenylate control over succinate-dependent respiration are human gastric cancer-specific phenomena, Mol. Cell. Biochem. 370 (2012) 69-78, https://doi.org/10.1007/s11010-012-1399-3.

[50] H. Luuk, M. Plaas, S. Raud, J. Innos, S. Sutt, H. Lasner, U. Abramov, K. Kurrikoff, S. Koks, E. Vasar, Wfs1-deficient mice display impaired behavioural adaptation in stressful environment, Behav. Brain Res. 198 (2009) 334-345, https://doi.org/10. 1016/j.bbr.2008.11.007.

[51] A.V. Kuznetsov, V. Veksler, F.N. Gellerich, V. Saks, R. Margreiter, W.S. Kunz, Analysis of mitochondrial function in situ in permeabilized muscle fibers, tissues and cells, Nat. Protoc. 3 (2008) 965-976, https://doi.org/10.1038/nprot.2008.61.

[52] M. Puurand, K. Tepp, A. Klepinin, L. Klepinina, I. Shevchuk, T. Kaambre, Intracellular energy-transfer networks and high-resolution respirometry: a convenient approach for studying their function, Int. J. Mol. Sci. 19 (2018), https://doi. org/10.3390/ijms19102933.

[53] M. Varikmaa, R. Bagur, T. Kaambre, A. Grichine, N. Timohhina, K. Tepp, I. Shevchuk, V. Chekulayev, M. Metsis, F. Boucher, V. Saks, A.V. Kuznetsov, R. Guzun, Role of mitochondria-cytoskeleton interactions in respiration regulation and mitochondrial organization in striated muscles, Biochim. Biophys. Acta 1837 (2014) 232-245, https://doi.org/10.1016/j.bbabio.2013.10.011.

[54] R. Guzun, M. Gonzalez-Granillo, M. Karu-Varikmaa, A. Grichine, Y. Usson, T. Kaambre, K. Guerrero-Roesch, A. Kuznetsov, U. Schlattner, V. Saks, Regulation of respiration in muscle cells in vivo by VDAC through interaction with the cytoskeleton and MtCK within mitochondrial interactosome, Biochim. Biophys. Acta 1818 (2012) 1545-1554, https://doi.org/10.1016/j.bbamem.2011.12.034.

[55] A. Klepinin, L. Ounpuu, R. Guzun, V. Chekulayev, N. Timohhina, K. Tepp, I. Shevchuk, U. Schlattner, T. Kaambre, Simple oxygraphic analysis for the presence of adenylate kinase 1 and 2 in normal and tumor cells, J. Bioenerg. Biomembr. 48 (2016) 531-548, https://doi.org/10.1007/s10863-016-9687-3.

[56] D. Pesta, E. Gnaiger, High-resolution respirometry: OXPHOS protocols for human cells and permeabilized fibers from small biopsies of human muscle, Methods Mol. Biol. 810 (2012) 25-58, https://doi.org/10.1007/978-1-61779-382-0 3.

[57] V.A. Saks, V.I. Veksler, A.V. Kuznetsov, L. Kay, P. Sikk, T. Tiivel, L. Tranqui, J. Olivares, K. Winkler, F. Wiedemann, W.S. Kunz, Permeabilized cell and skinned fiber techniques in studies of mitochondrial function in vivo, Mol. Cell. Biochem. 184 (1998) 81-100.

[58] R. Paasuke, M. Eimre, A. Piirsoo, N. Peet, L. Laada, L. Kadaja, M. Roosimaa, M. Paasuke, A. Martson, E. Seppet, K. Paju, Proliferation of human primary myoblasts is associated with altered energy metabolism in dependence on ageing in vivo and in vitro, Oxidative Med. Cell. Longev. 2016 (2016) 8296150, https://doi.org/
$10.1155 / 2016 / 8296150$.

[59] E. Seppet, M. Eimre, N. Peet, K. Paju, E. Orlova, M. Ress, S. Kovask, A. Piirsoo, V.A. Saks, F.N. Gellerich, S. Zierz, E.K. Seppet, Compartmentation of energy metabolism in atrial myocardium of patients undergoing cardiac surgery, Mol. Cell. Biochem. 270 (2005) 49-61, https://doi.org/10.1007/s11010-005-3780-y.

[60] K.J. Livak, T.D. Schmittgen, Analysis of relative gene expression data using realtime quantitative PCR and the 2(-Delta Delta C(T)) method, Methods 25 (2001) 402-408, https://doi.org/10.1006/meth.2001.1262.

[61] V. Saks, T. Kaambre, R. Guzun, T. Anmann, P. Sikk, U. Schlattner, T. Wallimann, M. Aliev, M. Vendelin, The creatine kinase phosphotransfer network: thermodynamic and kinetic considerations, the impact of the mitochondrial outer mem brane and modelling approaches, Subcell. Biochem. 46 (2007) 27-65.

[62] P.P. Dzeja, K. Hoyer, R. Tian, S. Zhang, E. Nemutlu, M. Spindler, J.S. Ingwall, Rearrangement of energetic and substrate utilization networks compensate for chronic myocardial creatine kinase deficiency, J. Physiol. 589 (2011) 5193-5211, https://doi.org/10.1113/jphysiol.2011.212829.

[63] M. Eimre, S. Kasvandik, M. Ivask, S. Koks, Proteomic dataset of wolframin-deficient mouse heart and skeletal muscles, Data in Brief 21 (2018) 616-619, https://doi. org/10.1016/j.dib.2018.10.015.

[64] A.M. Rossi, H.M. Eppenberger, P. Volpe, R. Cotrufo, T. Wallimann, Muscle-type MM creatine kinase is specifically bound to sarcoplasmic reticulum and can support $\mathrm{Ca} 2+$ uptake and regulate local ATP/ADP ratios, J. Biol. Chem. 265 (1990) 5258-5266.

[65] K. Tepp, N. Timohhina, M. Puurand, A. Klepinin, V. Chekulayev, I. Shevchuk, T. Kaambre, Bioenergetics of the aging heart and skeletal muscles: modern concepts and controversies, Ageing Res. Rev. 28 (2016) 1-14, https://doi.org/10.1016/j.arr. 2016.04.001.

[66] S. Zervou, X. Yin, A.A. Nabeebaccus, B.A. O'Brien, R.L. Cross, D.J. McAndrew, R.A. Atkinson, T.R. Eykyn, M. Mayr, S. Neubauer, C.A. Lygate, Proteomic and metabolomic changes driven by elevating myocardial creatine suggest novel metabolic feedback mechanisms, Amino Acids (2016) 1-13, https://doi.org/10.1007 s00726-016-2236-x.

[67] R. Porosk, A. Terasmaa, R. Mahlapuu, U. Soomets, K. Kilk, Metabolomics of the Wolfram syndrome 1 gene (Wfs1) deficient mice, OMICS 21 (2017) 721-732, https://doi.org/10.1089/omi.2017.0143.

[68] M. Karu-Varikmaa, M. Saaremäe, P. Sikk, T. Käämbre, M. Metsis, V. Saks, Regulation of mitochondrial respiration by different tubulin isoforms in vivo, Biophys. J. 100 (2011) 459a.

[69] T.K. Rostovtseva, S.M. Bezrukov, VDAC inhibition by tubulin and its physiological implications, Biochim. Biophys. Acta 1818 (2012) 1526-1535, https://doi.org/10. 1016/j.bbamem.2011.11.004.

[70] M. Eimre, K. Paju, N. Peet, L. Kadaja, M. Tarrend, S. Kasvandik, J. Seppet, M. Ivask, E. Orlova, S. Koks, Increased Mitochondrial Protein Levels and Bioenergetics in the Musculus Rectus Femoris of Wfs1-Deficient Mice, Oxidative Medicine and Cellular Longevity, v2018, (2018), https://doi.org/10.1155/2018/3175313 12p.

[71] M. Jastroch, A.S. Divakaruni, S. Mookerjee, J.R. Treberg, M.D. Brand, Mitochondrial proton and electron leaks, Essays Biochem. 47 (2010) 53-67, https://doi.org/10.1042/bse0470053.

[72] M.D. Brand, J.L. Pakay, A. Ocloo, J. Kokoszka, D.C. Wallace, P.S. Brookes, E.J. Cornwall, The basal proton conductance of mitochondria depends on adenine nucleotide translocase content, Biochem. J. 392 (2005) 353-362, https://doi.org/ 10.1042/BJ20050890.

[73] V. Napolioni, A.M. Persico, V. Porcelli, L. Palmieri, The mitochondrial aspartate/ glutamate carrier AGC1 and calcium homeostasis: physiological links and abnormalities in autism, Mol. Neurobiol. 44 (2011) 83-92, https://doi.org/10.1007/ s12035-011-8192-2.

[74] A. Prola, Z. Nichtova, J. Pires Da Silva, J. Piquereau, K. Monceaux, A. Guilbert, M. Gressette, R. Ventura-Clapier, A. Garnier, I. Zahradnik, M. Novotova, C. Lemaire, Endoplasmic reticulum stress induces cardiac dysfunction through architectural modifications and alteration of mitochondrial function in cardiomyocytes, Cardiovasc. Res. 115 (2019) 328-342, https://doi.org/10.1093/cvr/cvy197.

[75] C.M.F. Monaco, M.C. Hughes, S.V. Ramos, N.E. Varah, C. Lamberz, F.A. Rahman, C. McGlory, M.A. Tarnopolsky, M.P. Krause, R. Laham, T.J. Hawke, C.G.R. Perry, Altered mitochondrial bioenergetics and ultrastructure in the skeletal muscle of young adults with type 1 diabetes, Diabetologia 61 (2018) 1411-1423, https://doi. org/10.1007/s00125-018-4602-6. 